\title{
The Impact of State Tax Subsidies for Private Long-Term Care Insurance on Coverage and Medicaid Expenditures
}

\author{
Gopi Shah Goda*
}

November 1, 2010

\begin{abstract}
In spite of the large expected costs of needing long-term care, only 10-12 percent of the elderly population has private insurance coverage. Medicaid, which provides means-tested public assistance and pays for almost half of long-term care costs, spends more than $\$ 100$ billion annually on long-term care. In this paper, I exploit variation in the adoption and generosity of state tax subsidies for private long-term care insurance to determine whether tax subsidies increase private coverage and reduce Medicaid's costs for long-term care. The results indicate that the average tax subsidy raises coverage rates by 2.7 percentage points, or 28 percent. However, the response is concentrated among high income and asset-rich individuals, populations with low probabilities of relying on Medicaid. Simulations suggest each dollar of state tax expenditure produces approximately $\$ 0.84$ in Medicaid savings, over half of which funnels to the federal government.
\end{abstract}

JEL Codes: G22, H31, H51, H71, H75, I11, I18, I38, J14

Keywords: long-term care insurance, tax incentives, Medicaid, price elasticity, fiscal impact

*Stanford Institute for Economic Policy Research, Stanford University, 366 Galvez Street, Stanford, CA 94305 USA, (650) 906-4102, gopi.shah.goda@gmail.com

I am extremely grateful to David Cutler and Amy Finkelstein for their guidance and support. I would also like to thank Michael Boskin, Jeffrey Brown, Norma Coe, Avi Ebenstein, Richard Frank, David Grabowski, Damon Jones, Amanda Kowalski, Colleen Manchester, Kevin Mumford, Edward Norton, Anita Alves Pena, Jeffrey Rhoades, John Shoven, David Stevenson, Kathy Swartz, seminar participants at Harvard University and Stanford University, and participants at the Robert Wood Johnson Scholars in Health Policy Research Annual Meeting for helpful comments and discussion. Comments from the editor and two anonymous referees greatly improved the paper. All remaining errors are my own. Financial support from the Robert Wood Johnson Foundation is gratefully acknowledged. This paper previously circulated with the title "Do Tax Subsidies for Private Insurance Reduce Medicaid Costs? Evidence from the Market for Long-Term Care Insurance" 


\section{Introduction}

In 2007, the United States spent $\$ 2.2$ trillion on health care, amounting to 16.2 percent of GDP. The publicly-financed portion of this spending includes not only amounts spent by Medicare and Medicaid ( $\$ 432.1$ billion and $\$ 328.9$ billion, respectively) but also the revenue loss that stems from the exclusion of employer-sponsored health insurance from individual income. This loss, currently the single largest tax expenditure, amounted to $\$ 145$ billion in $2007 .{ }^{1}$

Economists have studied several aspects of the costs and benefits of providing these tax incentives, including their ability to reduce the number of uninsured, the elasticity of firms offering health insurance to their workers, insurance-induced "job lock," and distributional impacts, among others. The results of these studies are important in assessing implications of removing or expanding subsidies for health insurance. In this paper, I examine the effect of tax incentives for private longterm care insurance on rates of insurance coverage and Medicaid expenditures for long-term care.

The current financing of long-term care expenditures in the U.S. differs from the rest of health care spending. Only 10-12 percent of the elderly population currently has private long-term care insurance and Medicaid pays for almost half of long-term care costs. By contrast, private insurance coverage is prevalent for acute health care and Medicaid pays only 15 percent of health care expenditures as a whole (NHA, 2010). The low coverage rate of private long-term care insurance is in spite of the substantial probability of needing assistance with activities of daily living and the high costs of long-term care services if care is needed.

Unlike private health insurance which has historically been heavily subsidized by the government through tax subsidies, private long-term care insurance did not enjoy tax preferences prior to the early 1990s. A limited federal subsidy was offered beginning in 1997, and in recent years, several states passed tax subsidy initiatives: while only three states had tax incentives for private long-term care insurance in 1996, by 2008, twenty-four states and the District of Columbia had adopted a tax subsidy for long-term care insurance premiums (see Figure 1). Furthermore, there is continuing interest at both the state and federal level to provide additional tax subsidies for private insurance.

\footnotetext{
${ }^{1}$ Joint Committee on Taxation, Tax Expenditures for Health Care (JCX-66-08), July 31, 2008, available at http://www.jct.gov. The figure cited does not include payroll tax revenue losses from the exclusion of employersponsored health insurance.
} 
The push towards providing tax subsidies for private long-term care insurance arose from a desire among policymakers to shift long-term care costs away from Medicaid. However, the efficiency considerations of such policies depend not only on net government spending (which influences the excess cost of raising government revenue through income taxation) but also on the effects of tax subsidies on private insurance coverage. Higher levels of private insurance coverage implies a large reduction in out-of-pocket expenditure risk, and may lead to greater access, higher quality, lower reliance on informal caregiving, and a reduction in adverse selection. Even if government expenditures for long-term care remain unchanged, financing long-term care through tax subsidies rather than through Medicaid could still improve efficiency if Medicaid's eligibility requirements distort savings and work decisions or overall nursing home quality is lower because Medicaid pays facilities less than market rates.

This paper focuses on two specific questions related to the implementation of tax subsidies for private long-term care insurance. The first is, how do tax subsidies affect rates of private long-term care insurance coverage? The variation in the adoption and generosity of tax subsidy programs across states and over time provides an ideal setting to examine this question. Figure 2 shows longterm care insurance coverage rates in the nationally-representative Health and Retirement Study (HRS) for individuals in states that never implemented a tax incentive (control states) and in states that implemented a tax subsidy for long-term care insurance between 1998 and 2001 (accounting for the majority of observations in treatment states). The figure shows that while coverage rates in the control and treatment states were similar prior to implementation of the tax subsidies, longterm care insurance coverage increased significantly in treatment states while remaining almost flat in control states. The growth in coverage is highly correlated with the introduction of tax incentive programs. Controlling for observable differences across states and time, I find that tax incentives are effective in inducing purchase of private long-term care insurance: implementation of the average tax subsidy increases purchase rates by 2.7 percentage points, or approximately 28 percent.

The second question that this study addresses is whether tax subsidies for private long-term care insurance are expected to reduce net government expenditures. I find that the highest response to the tax incentives comes from individuals who are asset rich and have high income, groups who are less likely to rely on Medicaid for their long-term care. Therefore, despite the relatively large 
response to the tax subsidies, simulations that take into account that the subsidy-induced response in insurance coverage varies with wealth suggest that tax incentives are unlikely to substantially reduce government net expenditures. For each dollar of state tax expenditure, Medicaid saves approximately $\$ 0.84$ in long-term care expenses, more than half of which is funneled to the federal government which jointly funds Medicaid. While the policy is net savings for the middle of the wealth distribution, those savings are overwhelmed by substantial net costs at the high end. The variability in the net cost across the wealth distribution highlights the fact that estimating the response to tax subsidies differentially by factors that determine Medicaid eligibility can lead to conclusions opposite from those drawn using estimates of average responsiveness, a key contribution of this paper.

The variation in the after-tax price caused by the implementation of tax subsidies also allows me to estimate the responsiveness of private long-term care insurance purchase to the after-tax price, of which there is little empirical evidence. I employ a simulated instrumental variables (IV) approach where the instrument for the after-tax price is equal to the average after-tax price for a nationally representative sample of 5,000 individuals in each state and year by educational attainment. This approach isolates variation in the after-tax price arising from the tax subsidy and eliminates bias stemming from potential correlation between one's marginal tax rate and their demand for long-term care insurance. The panel nature of the HRS also allows me to perform estimation using individual fixed effects. My most-preferred estimate of the elasticity with respect to the after-tax price is -3.3 . This estimate is identified solely by the variation in the after-tax price from changes in state tax incentive programs. It is important to note, however, that informational campaigns or increased awareness that could have accompanied tax subsidies may have at least partially contributed to the response, making it difficult to generalize the estimated elasticity to overall price changes. Moreover, caution should be taken when extrapolating the response to large price changes or comparing the elasticity estimated here with elasticities of goods with different levels of baseline ownership, such as health insurance.

The remainder of the paper proceeds as follows. Section 2 provides additional background on the market for long-term care insurance and tax preferences for private insurance. Section 3 describes the data and the estimation strategy, and the results of the empirical analysis are presented in 
Section 4. Section 5 describes the results of simulating the impact of tax subsidies on Medicaid long-term care expenditures and Section 6 concludes.

\section{$2 \quad$ Background and Related Literature}

\subsection{The market for private long-term care insurance}

The cost of long-term care expenditures, providing services to those with mental or physical impairments who cannot perform activities of daily living, amounted to $\$ 203$ billion (or 8.7 percent of total health care expenditures) for all ages in 2008 (NHA, 2010) and is expected to grow substantially due to the aging of the population $(\mathrm{CBO}, 2004){ }^{2}$ Long-term care represents a large financial risk for the elderly: 55 percent of individuals 85 and older experience some degree of chronic physical impairment (CBO 2004). In addition, the costs of long-term care services can be substantial. In 2009, the national average annual cost of nursing home care was $\$ 75,190$ for a semi-private room. Home health aides charge an average hourly rate of $\$ 19$; four hours of home health aide services daily would cost approximately $\$ 27,740$ per year (Genworth, 2010).

Medicaid, in addition to being the provider of health care for individuals with limited incomes and assets, provides long-term care services to those who meet certain income and asset eligibility criteria. $^{3}$ Medicare, the federal program which provides health insurance to individuals over age 65 , covers only limited stays in skilled nursing facilities following an acute health event, and some home health care for these eligible individuals. The next largest source of long-term care financing after government sources is out-of-pocket payments (21 percent in 2008). Private insurance pays for a relatively small share of nursing home and home health care expenses, accounting for less than 8 percent of expenditures in 2008 (NHA, 2010).

Norton (2000) and Brown and Finkelstein (2009) provide excellent reviews of the possible reasons for a thin insurance market. Demand-side reasons include difficulty in understanding longterm catastrophic risks and misconceptions about who pays for long-term care. Eighty-three percent of non-buyers cite cost as an important or very important reason they do not purchase private

\footnotetext{
${ }^{2}$ These and earlier figures refer to the costs of formal paid care provided in nursing homes and by home health care agencies provided in NHA (2010). The cost of providing informal care in terms of the market wage for these services is roughly of the same order of magnitude (Arno et al., 1999).

${ }^{3}$ The eligibility criteria for Medicaid long-term care services differ from state to state but the criteria are within federally set guidelines.
} 
long-term care insurance (AHIP, 2007). It has also been shown that the presence of Medicaid may explain crowd out of private insurance purchase for at least two-thirds of the wealth distribution (Brown and Finkelstein 2008, Brown, Coe and Finkelstein 2007).

Supply-side reasons for the lack of private long-term care insurance coverage include high administrative costs. The majority of long-term care insurance policies are sold through the individual market. ${ }^{4}$ Brown and Finkelstein (2007) show that only approximately 49 cents of each dollar of premiums is paid out in benefits, lower than those estimated for other types of insurance. ${ }^{5}$ These high loading factors provide evidence for market failures such as high transaction costs, imperfect competition, asymmetric information, or long-term dynamic contracting problems (Brown and Finkelstein, 2007).

\subsection{Tax preferences for private long-term care insurance}

Figure 1 shows the states which offered a tax subsidy for private long-term care insurance during the sample period and their relative generosity as a percentage of annual premium costs. ${ }^{6}$ The subsidies take the form of tax deductions or tax credits as described in more detail in Appendix A. Appendix B describes the methods used to obtain the value of each subsidy as a percentage of premium.

Federal legislation in the 1996 Health Insurance Portability and Accountability Act (HIPAA) enacted a tax preference for long-term care insurance in the federal tax code by designating that premiums for long-term care insurance could be counted toward the federal tax deduction for unreimbursed medical expenses. Unreimbursed medical expenses, however, must be over 7.5 percent of adjusted gross income (AGI) to be granted a tax deduction, and this deduction is only available to households who itemize deductions on their federal tax return. These restrictions imply that a relatively small set of individuals are eligible for this tax subsidy.

\footnotetext{
${ }^{4}$ Group policies are increasingly offered by employers and represent a growing segment of the market. According to the U.S. Bureau of Labor Statistics, 12 percent of workers in private industry had access to long-term care insurance through their employer in 2006.

${ }^{5}$ Mitchell et al. (1999) estimate loads of 15-25 cents per dollar for life annuities and Newhouse (2004) estimates loads are 6-10 cents for group health insurance and 25-40 cents for individual health insurance.

${ }^{6}$ States that implicitly offer the same subsidy at the state level because the tax base for the state return is the same as the federal return described in the following paragraph are not coded as having a tax subsidy in Figure 1 or subsequent analyses.
} 
Many prior analyses of tax subsidies for private long-term care insurance are based on qualitative analysis or simulations, lacking empirical evidence (e.g. Wiener et al. (1994), Cohen and Weinrobe (2000), Wiener et al. (2000)). In the course of developing estimates of the fiscal impact of tax incentives, it appears that policymakers generally either assumed no behavioral response or relied on a 1994 study quantifying the difference in Medicaid expenditures for long-term care among those with and without private insurance (Cohen et al., 1994). However, this study bears no mention of tax incentives at all and is ill-suited for this purpose. These studies and more recent empirical work (Courtemanche and He 2009, Johnson et al. 2007, Stevenson et al. 2009) do not examine a key factor in determining the impact of higher rates of long-term care insurance on Medicaid expenditures: namely, that the impact on Medicaid depends crucially on the likelihood of those who respond to the tax incentives to otherwise become eligible for long-term care through Medicaid.

\section{Data and Estimation Strategy}

\subsection{Data source and sample}

The data used in this paper comes from the Health and Retirement Study (HRS), sponsored by the National Institute on Aging. The HRS began as a biannual panel study on respondents age 51-61 in 1992 (born in 1931-1941) and their spouses. A separate sample, denoted as Asset and Health Dynamics among the Oldest Old (AHEAD) and consisting of cohorts born before 1923, was surveyed in alternate years until these samples were merged in 1998. At this time, two more samples were added: the War Baby (WB) sample, made up of those born from 1942 through 1947, and the Children of the Depression Age (CODA) sample, containing cohorts born from 1924 through 1930 (i.e. the missing birth cohorts between the HRS and AHEAD samples). All samples were merged for the purposes of this study. The respondents and their spouses were interviewed every two years, and the latest available survey responses comprising the eighth wave of the survey were taken in 2006. The survey contains a large amount of information regarding demographics, health status, family structure, housing, work history and current employment, disability, retirement plans, net worth, income, and insurance coverage.

Similar to the approaches used in Brown, Coe and Finkelstein (2007) and Courtemanche and He (2009), the analysis is limited to individuals aged 50-69, the prime buying age for long-term 
care insurance. $^{7}$ Only Waves 3-8 (sampled between 1996-2006) of the HRS are used in the analysis due to ambiguous question wording in the first two waves of the survey. ${ }^{8}$ The sample also excludes self-employed respondents whose treatment of health insurance premiums differ. Restricted access was obtained to match the HRS with state identifiers that are not part of the publicly available dataset. In addition, this dataset was augmented with data describing characteristics of state tax incentives for long-term care insurance which were collected from historical state tax return forms for all states from 1995 onwards. State level data on nursing facility occupancy rates, nursing home beds per 1,000 people age 65 and over, percent of state population age 65 and over, average nursing home private pay and Medicaid rates, and Medicaid eligibility data were merged from various sources. ${ }^{9}$ The final sample includes 52,992 observations on 15,822 unique individuals. The dependent variable in the regression analyses that follow is a binary variable indicating coverage by private long-term care insurance.

In each wave of the survey, approximately 10 percent of the respondents have private long-term care insurance. Table 1 displays characteristics of the sample by long-term care insurance coverage status. The table highlights the fact that long-term care insurance coverage is associated with more assets, higher income, and higher levels of education. There is no large difference in age or gender by coverage status. Approximately 30 percent of the observations were sampled in a state and year where a tax incentive for long-term care insurance was available, with a higher percentage living in a state with a deduction than a credit.

The level of private long-term care insurance coverage varies significantly across different observable characteristics. Table 2 summarizes coverage rates across subsamples before implementation of any tax incentives, and the average subsidy levels available to these different groups. In general, due to the fact that the likelihood of coverage is highly correlated with income and the subsidies tend to be more valuable to high-income individuals, the highest subsidies are offered to populations with relatively high pre-subsidy coverage rates.

\footnotetext{
${ }^{7}$ In a survey of buyers described in AHIP (2007), over 75 percent of buyers are in this age group. The average age of buyers of long-term care insurance from this survey is 61 .

${ }^{8}$ See appendix in Finkelstein and McGarry (2006) for a complete discussion.

${ }^{9}$ Nursing facility occupancy rates, beds data, and demographic data were obtained from AARP's Across the States reports, various years. Nursing home private pay rates were available from 2002-2007 from MetLife Nursing Home Surveys, various years. A missing data binary variable for years prior to 2002 is also included. Medicaid rates for 1996-2004 and Medicaid eligibility data were generously provided by David Grabowski. Further discussion regarding these data can be found in Grabowski et al. (2004) and Grabowski and Gruber (2007) and summary statistics of these data are available upon request.
} 


\subsection{Identification strategy}

The first approach taken in this paper is to formalize the relationship highlighted in Figure 2 to determine whether the presence of a tax incentive led to a higher probability of private long-term care insurance coverage controlling for observable individual-level and state-level characteristics. Specifically, I estimate the equation:

$$
L T C I_{i}=\gamma S U B S I D Y_{s t}+\beta X_{i}+\omega_{t}+\sigma_{s}+\mu_{i}+\varepsilon_{i s t}
$$

The dependent variable $L T C I_{i}$ is equal to one if individual $i$ who lives in state $s$ has private longterm care insurance in year $t$. The variable $S U B S I D Y_{s t}$ is a binary variable that indicates whether state $s$ has a subsidy at time $t . X_{i}$ is a vector of individual- and state-level characteristics, including controls for education, gender, marital status, age, race, income, assets, number of children, retirement status and health status, and the state-level characteristics mentioned previously. This vector also includes a binary variable that indicates whether the individual is eligible to receive a federal subsidy under HIPAA. ${ }^{10}$ Year fixed effects $\omega_{t}$ control for general trends in private long-term care insurance coverage. State fixed effects $\sigma_{s}$ control for unobservable time-invariant state characteristics such as state nursing home quality and costs of long-term care, presence of Partnership insurance policies, and residents' taste for insurance that may vary systematically. The panel nature of the dataset also allows estimation using individual fixed effects to estimate withinperson effects of tax subsidies on insurance coverage. Specifications which include individual fixed effects, denoted by $\mu_{i}$, omit time-invariant individual controls such as race, gender, and education. Standard errors are clustered at the state level to account for potential correlation of the error terms within states.

The estimate of $\gamma$ in Equation 1 represents the effect the presence of a tax subsidy had on long-term care insurance coverage. Estimation in specifications with state fixed effects only utilizes variation within states over time in tax incentive programs. The identifying assumption for these models is therefore the absence of state-specific time trends in coverage rates correlated with $S U B S I D Y$ that would have caused trends in private long-term care insurance coverage to

\footnotetext{
${ }^{10}$ This binary variable is equal to 1 for individuals who itemize their medical expenses in years 1997 onward.
} 
differ without implementation of the tax subsidy. With the addition of individual fixed effects, identification comes only from within-person changes in SUBSIDY.

The second approach taken is to exploit differences in the value of the tax subsidy. The variable TAXPRICE denotes the after-tax price of $\$ 1$ of private long-term care insurance in terms of foregone consumption. ${ }^{11}$ I estimate the equation:

$$
L T C I_{i}=\delta T A X P R I C E_{i s t}+\beta X_{i}+\omega_{t}+\sigma_{s}+\mu_{i}+\nu_{i s t}
$$

This approach differs from the method used in Equation 1 because it treats tax incentives that provide a larger value differently from tax incentives that do not heavily subsidize premiums. The variable $T A X P R I C E$ varies by state and year with the implementation of the tax subsidy. It also varies at the individual level, in many cases with the individual's marginal tax rate. Running OLS on Equation 2 implies that the estimate of $\delta$ is identified off of (1) changes in tax incentives for long-term care insurance, and (2) non-linearities in the state's tax schedule, after controlling for the individual's state of residence, income, and other covariates. The concern in the OLS estimate is that the control variables may not completely account for potential correlation between marginal tax rates and individual demand for insurance. The resulting bias could go in either direction. For instance, there may be a negative correlation between TAXPRICE and unobservable individual components of private long-term care insurance demand if insurance is a normal good and the effect of income is not properly accounted for by $X$. A positive correlation could arise if individuals who value insurance are also taking other actions to reduce their marginal tax rate.

Therefore, I also instrument for TAXPRICE with a set of simulated instruments where the instrument in each state and year is equal to the average after-tax price for a nationally representative sample of 5,000 individuals, similar to the approach developed in Currie and Gruber (1996). Because the after-tax price is calculated for the same set of individuals, the only variation in the instrument comes from changes in tax subsidies for long-term care insurance. To allow the value of the subsidy to change differentially for individuals in different socioeconomic groups, the instrument is averaged separately for low education (high school or less) and high education (some college or more) groups. The IV estimates of $\delta$ are therefore identified by changes in the after-tax

\footnotetext{
${ }^{11}$ Details regarding the calculation of the state marginal tax rate and the after-tax price of private long-term care insurance can be found in Appendix B.
} 
price arising from the tax subsidies and not contaminated by potential unobserved factors correlated with the individual's marginal tax rate and insurance purchase decisions. This methodology follows several other studies in the health insurance literature that use an IV strategy to address potential correlation between tax rates and insurance purchase (e.g. Royalty (2000), Finkelstein (2002), Gruber and Lettau (2004)). The average simulated after-tax price is a valid instrument as it is highly correlated with TAXPRICE, and has no direct bearing on an individual's long-term care insurance purchase decision.

\section{Results and Interpretation}

\subsection{Main results: The effect of tax incentives on long-term care insurance coverage}

Figure 2 provided suggestive evidence that tax incentives had a significant causal effect on the purchase of private long-term care insurance, but did not control for other individual or state characteristics that may have been changing over time. The results of the regression described by Equation 1 are summarized in Table 3 and confirm that the tax incentives had a significant impact on private long-term care insurance coverage rates after controlling for other factors. Column 1 includes only SUBSIDY. Column 2 adds in state and year fixed effects, and Column 3 adds all control variables. Column 4 represents the fully-specified model, including all time-varying control variables and individual fixed effects. The results in Column 4 indicate that the presence of a tax incentive for long-term care insurance increased the probability that an individual will be covered by 2.7 percentage points. This coefficient is precisely estimated and statistically significant at the 1 percent level. At the pre-subsidy coverage rate of 9.5 percent, the implementation of a tax subsidy is associated with a 28 percent increase in the probability of coverage.

Table 4 displays the OLS and IV estimates of $\delta$, the coefficient on the after-tax price of private long-term care insurance in Equation 2. As in Table 3, the first set of results in each row contains no other controls; the second set adds state and year fixed effects; the third set adds control variables; and the final set includes individual fixed effects. The IV estimates of the coefficient of $T A X P R I C E$ are significantly different from zero and stable across specifications. First-stage regression results confirm the power of the simulated after-tax price in predicting the actual aftertax price an individual faces. The hypothesis that the instrument should be excluded from the first 
stage can be strongly rejected with F-statistics in the thousands. ${ }^{12}$ The OLS estimates are largely identified off of the non-linearities in the tax schedule which may produce bias if marginal tax rates are correlated with long-term care insurance coverage after controlling for observable factors. The IV estimates are more negative than the OLS estimates, suggesting that there are unobservable factors that are positively correlated with private long-term care insurance coverage that are also positively correlated with the after-tax price after controlling for $X$, biasing the OLS estimate of $\delta$ upward. There are several candidates for these unobservable factors. For example, bequest motives are highly predictive of private long-term care insurance purchase because spending down one's wealth to qualify for Medicaid benefits eliminates the possibility of leaving an estate for one's heirs. A person with a large bequest motive may be taking advantage of tax-deferred or tax-free savings vehicles, and consequently, after controlling for income, would have a lower marginal tax rate and a higher after-tax price. Similarly, an individual who is financially savvy and familiar with the tax code (or who has access to a paid tax preparer) may be more likely to respond to long-term care insurance tax incentives and also more likely to take advantages of other tax incentives that reduce her marginal tax rate.

Because of the potential bias arising from identification off of non-linearities (or changes in non-linearities) in the tax schedule and contamination from measurement error in TAXPRICE, the estimate in Panel B, Column 4 of Table 4 represents my preferred estimate of the response in coverage to changes in the after-tax price from tax incentives for long-term care insurance. An estimated coefficient of -0.315 means that a 10 percent decrease in the after-tax price of longterm care insurance increases the probability of coverage by 3.15 percentage points. The implied elasticity with respect to the after-tax price is simply $-0.315 / 0.0949=-3.32$.

It is important to note that the response that I estimate may be attributed to changes in the after-tax price of long-term care insurance when the true response was at least partially due to informational campaigns or media coverage correlated with implementation of the tax incentives, increased salience of long-term care costs and risks, or the perception of government endorsement. With the data available, it is difficult to definitively determine the extent to which information drove the observed response or the precise mechanism through which this effect operated. However, it is not unreasonable to think that the reduction in price from a tax incentive specifically for long-term

\footnotetext{
${ }^{12}$ The complete first-stage results are not reported but available upon request.
} 
care insurance elicited a larger response than a different kind of price reduction. Therefore, caution should be taken when applying the price elasticities estimated here more generally.

\subsection{Relationship to other estimates}

Few studies have provided estimates of the price elasticity of long-term care insurance. Cramer and Jensen (2006) estimate logit models of demand as a function of price and find elasticities in the -0.23 to -0.87 range. However, their results are driven by the variation in premiums by age rather than a source of exogenous variation. Johnson et al. (2007) estimate hazard models of time to purchase long-term care insurance as a function of the net benefit that individuals expect to derive from the policy and estimate a price elasticity of demand of -0.75 . Neither estimate accounts for the potential bias created by unobservable components of individual demand.

Courtemanche and He (2009) study the change in the federal tax treatment of long-term care insurance premiums and estimate an elasticity of -3.9 , within the range of IV estimates produced here. However, the approach taken in this study relies on fewer assumptions relating to the exogeneity of treatment status. The validity of Courtemanche and He (2009)'s approach depends on the persistence of itemizing status and medical expenses and the assumption that the decision to file taxes and itemize medical expenses is exogenous to long-term care insurance purchase. Moreover, many of the state initiatives are more broadly defined, applying to a larger segment of the population than the federal incentive. Courtemanche and $\mathrm{He}$ (2009) find that 14 percent of people in their sample itemized medical expenses and are likely to be affected by the federal tax incentive. It is uncertain, therefore, whether their results can be generalized to the elderly population.

The estimated price elasticity is larger in magnitude than those generally found for health insurance. Estimates of price elasticities for health insurance are between 0 and -3 , with the bulk between -0.5 and $-1 .^{13}$ However, each elasticity estimate is valid only for a local range of coverage rates, and the much higher baseline ownership rates for health insurance (65-70 percent) make

\footnotetext{
${ }^{13}$ One strand of literature examines the elasticity of insurance coverage (Gruber and Poterba (1994), Marquis and Long (1995), Chernew, Frick and McLaughlin (1997), Auerbach and Ohri (2006)). Because the primary channel of health insurance coverage is through the employer, several studies also examine the price elasticity of firms offering insurance (Feldman et al. (1997), Marquis and Long (2001), Chernew and Leibowitz (1992), Royalty (2000), Finkelstein (2002), Gruber and Lettau (2004)).
} 
these values difficult to compare. The high estimated price elasticity for long-term care insurance is consistent with survey responses that indicate cost as a large factor in purchasing private coverage.

\subsection{Effects on the intensive margin}

Because tax subsidies reduce the after-tax price of long-term care insurance, it is possible that more generous policies were purchased as a result. To examine the effect on the intensive margin, I estimate analogs of Equation 1 with indicators of two optional policy features on the left-hand side for the whole sample of respondents: whether the policy contains a rider for inflation protection that prevents benefits from eroding over time, and whether the policy covers both nursing home care and home care, providing covered individuals with more flexibility to meet their long-term care needs. The results are summarized in Table 5. The estimates indicate that tax incentives increased the probability that individuals had inflation-protected coverage and coverage of both nursing home and home care by 1.2 and 2.5 percentage points relative to a base of 3.9 and 7.1 percent respectively. Tax incentives therefore appear to have affected long-term care insurance coverage decisions both at the extensive and intensive margin.

The higher rates of coverage by both of these optional benefits represents an increase in the comprehensiveness of coverage provided by private insurance contracts. In particular, the lack of inflation protection provided by basic policies leave many exposed to considerable out-of-pocket risk and at greater risk of relying on Medicaid. The associated increase in inflation-protected policies therefore represents a meaningful increase in the insurance value of private long-term care insurance.

\subsection{Heterogeneity in response to tax subsidies and price elasticities}

As was shown in Table 2, different subsamples of the population had varying degrees of pre-subsidy coverage of private long-term care insurance, and were also treated with different levels of subsidy because of the way the tax subsides were structured. The numerous and varied state tax incentives provide a rich setting to examine how responsiveness varies across observable characteristics. As will be shown in Section 5, the omission of this analysis from previous literature is important because the variation in response across factors that determine Medicaid eligibility is a key driver

of the impact on Medicaid costs. I therefore estimate fully-interacted versions of Equations 1 and 
2 to determine whether the response to tax incentives or the elasticity with respect to the after-tax price varies across observable characteristics such as income, wealth, education, retirement status, marital status, gender, age, self-reported health status, and limitations in activities of daily living (ADLs).

There is substantial heterogeneity in the estimated effect of tax subsidies on the probability of private long-term care insurance across many of these different observable characteristics, as summarized in Table 6. ${ }^{14}$ The most striking fact is that the response to tax incentives is significantly larger among individuals with high income and a large amount of assets. The estimated coefficients change in sign and are not statistically significant for the low income and low asset subsamples. Similar effects are present when the sample is cut by education status. Because of the strong correlation between income, assets, and education, it is difficult to disentangle the effects of these three characteristics separately. However, the evidence indicates that while state tax incentives do induce coverage of private long-term care insurance, the effect is seen mainly among groups with high income, a large amount of assets, and those who are more highly educated.

The results in Table 6 show that the response varies for particular groups; however it is difficult to determine whether this heterogeneity is simply because the value of the subsidy is greater for these groups or whether the behavioral response to a given level of subsidy differs. This question is addressed by estimating fully-interacted versions of Equation 2 where the after-tax price replaces the binary subsidy variable and is instrumented with the simulated instruments described earlier.

The results of these regressions are displayed in Table 7 . In Table 7, the same groups that show a strong response to tax subsidies (i.e., populations with high levels of education, income and wealth) exhibit price elasticities that are significantly larger in magnitude. Furthermore, groups with no detectable response have implied elasticities that are statistically insignificant and often of the wrong sign. These results suggest that high income and wealth groups have a higher level of behavioral response for a given level of subsidy and that raising the subsidy level among low income and wealth groups is unlikely to have a significant impact on private long-term care insurance coverage. This finding is consistent with Brown and Finkelstein (2008) who suggest that tax subsidies that are possible given the range of marginal tax rates in the U.S. are not large enough to overcome large implicit tax rates on private insurance premiums for low-wealth households.

\footnotetext{
${ }^{14}$ The results shown in Table 6 are from specifications analogous to Columns (3) and (4) in Table 3
} 


\subsection{Characteristics of tax-induced insurance purchasers}

In this section I explore the characteristics of the individuals induced to purchase private insurance coverage (the marginal purchasers) relative to the general population or the total population of long-term care insurance purchasers. In standard IV terminology, when the presence of a tax subsidy is an exogenous determinant of insurance purchase, the tax-induced purchasers are known as 'compliers' and estimates of the average characteristics of this population can be obtained following the approach proposed by Abadie (2002) and illustrated by Autor and Houseman (2005). ${ }^{15}$ Specifically, the average of characteristic $X$ for tax-induced purchasers of insurance is denoted by $\kappa(X)$ and calculated as follows:

$$
\kappa(X)=\frac{E[X \mid L T C I=1, S=1] \cdot E[L T C I \mid S=1]-E[X \mid L T C I=1, S=0] \cdot E[L T C I \mid S=0]}{E[L T C I \mid S=1]-E[L T C I \mid S=0]}
$$

where $S$ represents the presense of a tax subsidy and LTCI denotes long-term care insurance coverage.

The results of estimating the average value of selected characteristics for tax-induced insurance purchasers using Equation 3 are given in Table 8. Table 8 also includes the averages of the same selected characteristics for the general population, the population of long-term care insurance purchasers, and differences between these groups and the marginal purchasers. ${ }^{16}$ The results indicate that those induced to purchase long-term care insurance by the tax subsidy have higher income and assets, are more likely to be married, have higher levels of education, and are more likely to be white than the general population as well as the population of long-term care insurance purchasers as a whole. Tax-induced purchasers are less likely to report being in poor health status than the general population, but are of similar health status as those who hold long-term care insurance. The three groups do not vary significantly in age, gender, number of children, or retirement status.

While the average individual with long-term care insurance is already wealthier and more highly educated than the general population, tax-induced purchasers are even more so. Therefore, the

\footnotetext{
${ }^{15}$ Note that this method requires that the instrument (in this context, the presence of a tax subsidy) satisfies standard LATE assumptions.

${ }^{16}$ Standard errors of the differences are calculated using STATA's bootstrap package with resampling performed 1,000 times.
} 
results in Table 8 suggest that if the goal of tax subsidies was to increase insurance coverage among those who may not have otherwise afforded insurance, it is unlikely that this goal was fulfilled.

\subsection{Specification checks and falsification exercises}

\subsubsection{Specification checks}

The results shown are robust to a variety of different specifications. The above specifications were also estimated using the non-linear probit model and produce estimates that are extremely similar in magnitude, with marginal effects of SUBSIDY between 2.1 and 2.7 percentage points. Because the purchase of long-term care insurance is often a joint decision, the analysis was also done at the couple level in contrast to the above specifications which treat husbands' and wives' decisions separately. When modeling the coverage decision for couples, the analysis was done using two dependent variables: the first a binary variable that indicated whether at least one member of the couple was covered by private insurance, and the second a binary variable that indicated whether both members of the couple were covered. The pre-subsidy coverage rate for the less restrictive dependent variable was 12.7 percent, while only 3.7 percent of couples reported both having private long-term care insurance. The presence of a tax incentive was estimated to have a 2.2 percentage point (or 17 percent) increase using the first dependent variable, and a 1.3 percentage point (or 35 percent) increase using the second, broadly consistent with the reported results. The results are robust to the inclusion of the variable denoting whether the individual is eligible to receive the HIPAA deduction and constraining the instrument to be the same across education groups. Finally, the specifications were run omitting the South, an area with fewer tax incentives and potentially different regional trends. Under this sample selection, the estimated response of tax incentives was to increase coverage rates by 2.4 percentage points, similar to the estimates shown in Table 3 .

\subsubsection{Falsification test: comparison to alternative insurance purchase}

To increase our confidence that the response is not driven by shocks in insurance demand correlated with the implementation of subsidies for private long-term care insurance, I estimate the above specifications with dependent variables that denote either life insurance coverage or annuity 
income. $^{17}$ Because neither life insurance nor annuity income were tax-preferenced in the same pattern as private long-term care insurance, an estimated effect of $S U B S I D Y$ on life insurance or annuity demand would signify either unobservable shocks in demand for insurance that happened in conjunction with tax incentive implementation or non-zero gross cross-price elasticities between private long-term care insurance and these other insurance products. This exercise is in the spirit of Royalty (2000) which uses both state variation in marginal tax rates and comparison to non tax-preferenced fringe benefits as sources of identification of the price elasticity of health insurance.

The estimates of SUBSIDY on the probability of coverage are shown in Table 9. The estimated coefficients are generally small in magnitude relative to the mean of the dependent variable, often flip in sign, and are statistically insignificant. ${ }^{18}$ The fact that the tax incentives increased long-term care insurance coverage and did not have a strong detectable effect on other insurance purchase is consistent with the claim that unobserved trends in insurance demand common to these different types of insurance are not likely to be strongly biasing the estimates of $\gamma$ and $\delta$ described earlier.

\section{Simulating The Impact of Tax Incentives for Private Long-Term Care Insurance on Medicaid Costs}

The stated objective of implementing tax incentives at the state level is to reduce Medicaid expenditures for long-term care. Because the population purchasing insurance now will have most of their long-term care claims one to two decades from now, it is not possible to get an accurate assessment of the reduction in Medicaid long-term care expenditures from tax-induced purchase using currently available data. Therefore, in this section I use the results from this paper along with estimates from the literature to simulate the future fiscal impact of tax subsidies for private insurance.

\subsection{Simulation methods}

I simulate the impact of providing a tax subsidy for a 65 -year-old in each wealth decile $i$ and gender g. I define insurance coverage rates before and after the implementation of the subsidy as $P_{i}(I)$

\footnotetext{
${ }^{17}$ The definition of life insurance used is a policy that does not provide a cash value upon surrender of a policy. The HRS does not contain information on whether an individual has purchased an individual annuity, so the measure of annuity income used is whether the respondent is currently receiving income from an annuity.

${ }^{18}$ In results not reported, OLS and IV estimates of the coefficient on TAXPRICE provide very similar results.
} 
and $P_{i}^{\prime}(I)=P_{i}(I)+R_{i}$, respectively, where $R_{i}$ denotes the response to the tax incentive for wealth decile $i . M_{i, g}(I)$ and $M_{i, g}(N)$ represent the share of the expected present discounted value (EPDV) of long-term care expenditures with and without private insurance for wealth decile $i$ and gender $g$. The Medicaid share prior to and following the tax subsidy is therefore equal to $M_{i, g}(T)$ and $M_{i, g}^{\prime}(T)$ respectively as defined below:

$$
\begin{aligned}
& M_{i, g}(T)=P_{i}(I) \times M_{i, g}(I)+\left(1-P_{i}(I)\right) \times M_{i, g}(N) \\
& M_{i, g}^{\prime}(T)=P_{i}^{\prime}(I) \times M_{i, g}(I)+\left(1-P_{i}^{\prime}(I)\right) \times M_{i, g}(N)
\end{aligned}
$$

The expected Medicaid savings $E_{i, g}(S)$ for wealth decile $i$ and gender $g$ follows:

$$
E_{i, g}(S)=\left(M_{i, g}(T)-M_{i, g}^{\prime}(T)\right) \times E_{g}(L T C)
$$

where $E_{g}(L T C)$ is the EPDV of long-term care costs for an individual of gender $g$.

The expected cost of the tax expenditure for wealth decile $i$ and gender $g$ associated with the Medicaid savings, $E_{i, g}(C)$, is simply:

$$
E_{i, g}(C)=S_{i} \times P_{i}^{\prime}(I) \times \pi \times \sum_{t=0}^{T-65} \frac{p_{g, 65+t}}{(1+i)^{t}}
$$

where $S_{i}$ denotes the percentage subsidy offered to wealth decile $i, \pi$ denotes the annual premium, and $p_{g, 65+t}$ denotes the probability the policyholder is alive and not on claim at age $65+t .{ }^{19}$ The expression $\sum_{t=0}^{T-65} \frac{p_{g, 65+t}}{(1+i)^{t}}$ denotes the present value of an annual stream of $\$ 1$ payments that continue for the premium-paying duration valued with interest rate $i .^{20}$

\footnotetext{
${ }^{19}$ Note Equation 7 assumes that tax subsidies are available to both existing and tax-induced purchasers. However, in three states (MD, OR, and VA), only new policies are eligible for tax credits; therefore, the tax expenditure for these states would be significantly lower.

${ }^{20}$ The probability $p_{g, 65+t}=1-q_{g, 65+t}^{d}-q_{g, 65+t}^{c}$, where $q_{g, 65+t}^{d}$ is the probability of a policyholder dying at age $65+t$ and $q_{g, 65+t}^{c}$ is the probability a policyholder age $65+t$ goes on claim. $T$ is the maximum age of survival.
} 
Equations 6 and 7 together define the expected net government benefit of providing the tax subsidy, $E_{i, g}(N B)$, and the return per dollar of tax expenditure, $E_{i, g}(R)$ :

$$
\begin{aligned}
E_{i, g}(N B) & =E_{i, g}(S)-E_{i, g}(C) \\
E_{i, g}(R) & =\frac{E_{i, g}(S)}{E_{i, g}(C)}
\end{aligned}
$$

Medicaid is jointly funded by states and the federal government, and the federal share varies by state but is at least 50 percent. This feature of Medicaid creates an externality in either entity's decision to implement a tax incentive. In the case of a state tax subsidy, at least half of the savings are captured by the federal government while only the state bears the cost of the tax expenditure. Assuming Medicaid costs are shared equally between the state and federal government, the total expected net benefit can be broken down into the state's net benefit and the federal government's net benefit as follows:

$$
\begin{aligned}
E_{i, g}^{\text {state }}(N B) & =\frac{1}{2} E_{i, g}(S)-E_{i, g}^{\text {state }}(C) \\
E_{i, g}^{\text {federal }}(N B) & =\frac{1}{2} E_{i, g}(S)-E_{i, g}^{\text {federal }}(C)
\end{aligned}
$$

where $E_{i, g}(C)=E_{i, g}^{\text {state }}(C)+E_{i, g}^{\text {federal }}(C) .{ }^{21}$

\subsection{Simulation assumptions}

Implementation of the above procedure to estimate cost savings for the average long-term care insurance subsidy requires assumptions regarding its effect on coverage rates, Medicaid's long-term care costs for individuals with and without insurance, and premiums. I first determine pre-subsidy insurance coverage rates from the HRS by wealth decile. I assume the responses to the tax subsidy by low, medium, and high wealth given in Table 6 correspond to the $20^{t h}, 50^{\text {th }}$, and $80^{\text {th }}$ wealth percentiles, respectively and linearly interpolate response rates for the remaining wealth percentiles.

Table 10 partially reproduces Table 2 of Brown and Finkelstein (2008) which provides estimates of $M_{i, g}(I)$ and $M_{i, g}(N)$, Medicaid's share of the EPDV of long-term care expenditures by gender and wealth decile for 65-year-old individuals with and without private insurance. The private insurance

\footnotetext{
${ }^{21}$ The value $E_{i, g}^{\text {federal }}(C)$ is negative because the federal government gains revenue from state tax subsidies due to the deductibility of state and local taxes on federal tax returns for those who itemize. See Appendix B for more details.
} 
policy modeled provides a $\$ 100$ daily benefit, and the wealth percentiles reflect the distribution at age $65{ }^{22}$ This table shows that Medicaid shares of long-term care costs are declining in wealth and having private insurance reduces Medicaid expenditures more as wealth declines.

I use an annual premium of $\pi=\$ 2,000$, in line with premium estimates for a policy as modeled in the simulation results in Brown and Finkelstein (2008). The premium is assumed to be the same for both men and women, as premiums in the private long-term care insurance market are genderneutral. However, the EPDV of long-term care costs differ substantially by gender: $E_{f}(L T C)=$ $\$ 43,750$ for women and $E_{m}(L T C)=\$ 17,510$ for men. Annuity values were calculated assuming industry estimates of mortality and claim rates by gender for long-term care insurance policyholders taken from Corliss et al. (2007) and a 3 percent discount rate. The sensitivity to these assumptions is examined in Section 5.4

\subsection{Simulation results}

Figure 3(a) depicts the net benefit in dollars per 65-year-old at different points in the wealth distribution. The relationship between dollars saved and wealth is non-monotonic: the net benefit is negative for an individual at the $10^{t h}$ percentile, becomes positive for an individual at the $20^{t h}$, and increases until the $50^{\text {th }}$ percentile. At the high end of the wealth distribution, the net benefit is negative. On average, the large losses at the high end of the wealth distribution overwhelm the gains in the middle of the distribution and cost governments $\$ 27$ per 65 -year-old.

The non-monotonic nature arises because of two countervailing forces. At low levels of wealth, the potential Medicaid savings from higher private insurance coverage is large, but the response to the tax subsidy is low. At high levels of wealth, there is a large degree of response to the tax subsidy, but increased private insurance coverage does not substantially change the share of long-term care expenses paid for by Medicaid for these groups. The cost of the tax subsidy, by contrast, is monotonically increasing in wealth due to the higher subsidy rates available to highwealth individuals and higher rates of insurance coverage among these groups.

\footnotetext{
${ }^{22}$ Medicaid eligibility is simulated using a utility-maximization framework and probabilities of long-term care utilization from a transition model widely used in the industry. The model is solved using dynamic programming techniques and a 3 percent discount rate. On average, the model predicts that 55 percent of long-term care expenditures are paid for by Medicaid, broadly consistent with other estimates. The Medicaid income and asset threshold used in the simulation are the modal thresholds, used by 35 states.
} 
Figure 3(b) divides the net benefits between the federal and state government assuming Medicaid expenditures are shared equally. Because the tax expenditure is borne solely by the state, the state loses more in foregone tax revenues than their portion of Medicaid savings across the entire wealth distribution, spending on average $\$ 140$ per 65 -year-old. The federal government saves on average $\$ 113$ per 65-year-old without any associated outlay. ${ }^{23}$

In total, the savings from Medicaid per $\$ 1$ of tax expenditure is approximately $\$ 0.84$. More than half of these savings $(\$ 0.51)$ are conferred to the federal government, while the remainder (\$0.33) is kept with the state. The return is greater than $\$ 1$ for individuals between the $20^{t h}$ and the $60^{\text {th }}$ percentiles of the wealth distribution, and less for individuals with very high or very low amounts of wealth. Because the EPDV of long-term care costs is much greater for women and the cost of subsidizing their premiums is the same as for men, there is more to gain from Medicaid paying a reduced share of long-term care expenses for women. The result is that returns are greater for women than for men: $\$ 0.41$ for men and $\$ 1.25$ for women for each $\$ 1$ of tax expenditure.

Figure 3 highlights the importance of performing simulations using response rates that vary with factors related to Medicaid eligibility relative to developing cost estimates from average response rates, as in Courtemanche and He (2009). If the coefficients estimated in Table 3 were utilized along with Medicaid shares for individuals with median wealth, the average tax subsidy would appear to save $\$ 81$ per 65 -year-old and return $\$ 1.48$ in Medicaid savings for each $\$ 1$ of tax expenditure, in stark contrast with the simulation results that take heterogeneous responses into consideration. The error results from finding the net fiscal benefit at the average rather than the average of each wealth decile's net fiscal benefit.

\subsection{Sensitivity analysis}

The simulation results rely on the value of each input and the sensitivity to several factors is summarized below. Reducing the premium to $\$ 1,800$ (with no corresponding decrease in long-term care costs) decreases the net cost per 65-year-old from $\$ 27$ to $\$ 10$ and increases the total Medicaid savings per $\$ 1$ of tax expenditure from $\$ 0.84$ to $\$ 0.93$. Increasing the premium to $\$ 2,200$ increases the net cost to $\$ 44$ and decreases the savings to $\$ 0.76$ per $\$ 1$ of tax expenditure. Within this

\footnotetext{
${ }^{23}$ This savings includes $\$ 70$ in Medicaid savings and $\$ 43$ in increased federal tax revenues due to the smaller deduction of state taxes by itemizers. See Appendix B for more details regarding the interaction between state and federal tax revenues.
} 
wide range of premiums, however, the tax incentives are still expected to cost more than they save. Similar results are obtained by adjusting $E_{g}(L T C)$, the estimated EPDV of all long-term care costs, by 10 percent in either direction. Changing the discount rate assumption affects the expected cost savings because the Medicaid savings are further in the future relative to the premium subsidy, and the cost-benefit analysis is sensitive to the 3 percent discount rate assumed in the simulations. Adjusting the discount rate to 4.5 percent increases the net cost to $\$ 48$ and reduces the Medicaid savings to $\$ 0.66$ per $\$ 1$ of tax expenditure. Under the assumption that the discount rate is 1.5 percent, the policy becomes cost savings, saving $\$ 18$ per 65 -year-old and returning $\$ 1.09$ for each $\$ 1$ spent in tax expenditure.

\begin{tabular}{|lc|cc|}
\hline \multicolumn{4}{|c|}{ Sensitivity of Simulation Results to Parameter Estimates } \\
\hline \multirow{2}{*}{ Base Case Scenario } & & $E(N B)$ & $E(R)$ \\
\hline \multirow{2}{*}{ Premiums } & $+10 \%$ & $-\$ 27$ & $\$ 0.84$ \\
\hline \multirow{2}{*}{ Expected Long-Term Care Costs } & $-10 \%$ & $-\$ 10$ & $\$ 0.76$ \\
& $+10 \%$ & $-\$ 13$ & $\$ 0.93$ \\
\hline \multirow{2}{*}{ Discount Rate } & $-10 \%$ & $-\$ 41$ & $\$ 0.75$ \\
& $1.5 \%$ & $+\$ 18$ & $\$ 1.09$ \\
& $4.5 \%$ & $-\$ 48$ & $\$ 0.66$ \\
\hline
\end{tabular}

By assuming that the EPDV of long-term care expenditures does not change after coverage rates increase, the base simulation results implicitly assume no moral hazard. While Grabowski and Gruber (2007) find no evidence of moral hazard in nursing home utilization, empirical evidence suggests that home health care use is more subject to increased utilization through moral hazard (Weissert et al., 2005). The effect of moral hazard would be to decrease the expected Medicaid savings and therefore reduce the net benefit: smaller Medicaid shares through increased insurance coverage would be offset by higher Medicaid expenditures overall. Assuming that, for example, $E_{g}(L T C)$ is 5 percent higher for individuals with private insurance relative to those without private insurance increases the net cost per 65 -year old to $\$ 42$ and the Medicaid savings per $\$ 1$ of tax expenditure decreases to $\$ 0.75$. If $E_{g}(L T C)$ for the privately insured is 10 percent higher, the net cost increases to $\$ 57$ and the savings per $\$ 1$ of tax expenditure falls to $\$ 0.66$.

There are several additional assumptions behind these estimates. First, individuals who purchased insurance after implementation of the tax subsidy are assumed to have similar Medicaid shares as individuals who purchased insurance prior to the subsidy. This assumption is supported 
by the fact that these two groups do not differ greatly in their health status, income, and assets, as shown in the previous section. Second, as assumed in Brown and Finkelstein (2008), the EPDV of long-term care expenditures is equal across the wealth distribution. Third, the tax expenditure is assumed to stop only if a policyholder dies or goes on claim and therefore ceases paying premiums. Changes in the subsidy level, perhaps due to changes in filing status or income, are ignored. Fourth, the response among men and women to the tax subsidy was assumed to be the same, as supported by the results in Table 7 which showed no statistical difference in the response by gender. The simulations also assume that individuals do not move away from the state they received the subsidy from and in turn save another state's share of Medicaid expenditures rather than the state that bore the tax expenditure or lapse their policy. If there is a positive probability of either, the estimated net savings would be lower given the timing of the expenditure relative to the costs. Finally, interactions with other programs, such as a potential reduction in Medicare costs from having fewer Medicaid recipients, and other general equilibrium effects are ignored.

\section{Discussion and Conclusion}

This study builds on existing literature assessing the implications of expanding or contracting tax incentives for insurance. In this study, I find that tax subsidies for private long-term care insurance increased coverage by 2.7 percentage points, or 28 percent of pre-subsidy coverage rates. The identification of this result comes from changes within states and individuals over time in tax subsidy programs. The implied elasticity with respect to the after-tax price is approximately -3.3 .

While the tax incentives do seem to have induced insurance coverage, moving to the most generous subsidy (a tax credit worth 20 percent of premiums) would be unlikely to substantially reduce the proportion of the population that does not have adequate private insurance coverage for long-term care. Moreover, the effects are concentrated among high income and wealthier populations. As a result, tax incentives are unlikely to substantially reduce net government expenditures for long-term care. Simulations suggest that $\$ 1$ in state tax expenditure produces $\$ 0.84$ in Medicaid savings, more than half of which is captured by the federal government. One of the central contributions of the analysis is that it highlights the importance of estimating 
insurance coverage responses separately by factors that determine Medicaid eligibility, ignored in prior literature.

To have a larger effect on the allocation of long-term care financing, tax incentives would need to increase private insurance coverage for those who are at higher risk of spending down to Medicaid eligibility. Structuring tax incentives such that they target low-wealth populations and increasing awareness of long-term care risks among these groups may be influential, but it may be that without more comprehensive Medicaid reform to reduce market distortions, these populations are unlikely to respond to tax incentives by taking up private insurance. ${ }^{24}$

It is important to note that while the tax subsidies as currently structured appear to be unlikely to reduce Medicaid expenditures, they may be effective in counteracting myopia and the higher rates of coverage they induce may have other desirable consequences not evaluated here. These consequences may include a reduction in adverse selection and administrative loads, a reduction in out-of-pocket expenditure risk among the elderly, greater access to higher quality care, lower reliance on informal caregiving from spouses and children, and spillover effects to other potential consumers. Evaluating these effects remains an important area for future research.

\footnotetext{
${ }^{24}$ Brown and Finkelstein (2008) suggest a reform that would address both the means-tested nature of Medicaid and its secondary payer status: the reform would involve giving refundable tax credits equal to the expected present discounted value of the Medicaid benefits that are replaced by the private insurance. However, this policy would be difficult to implement in practice.
} 


\section{References}

Abadie, Alberto. 2002. "Bootstrap Tests for Distributional Treatment Effects in Instrumental Variable Models" Journal of the American Statistical Association, 97(457): 284-292.

AHIP. 2007. "Who Buys Long-Term Care Insurance? A 15-Year Study of Buyers and Non-Buyers, 1990-2005".

Arno, Peter S., Carol Levine, and Margaret M. Memmott. 1999. "The Economic Value of Informal Caregiving" Health Affairs, 18(2): 182-188.

Auerbach, David, and Sabina Ohri. 2006. "Price and the Demand for Nongroup Health Insurance" Inquiry, 43(2): 122-134.

Autor, David H., and Susan Houseman. 2005. "Do Temporary Help Jobs Improve Labor Market Outcomes for Low-Skilled Workers? Evidence from 'Work First"' National Bureau of Economic Research.

Brown, Jeffrey R., and Amy Finkelstein. 2007. "Why is the Market for Long-Term Care Insurance So Small?" Journal of Public Economics, 91(10): 1967-1991.

Brown, Jeffrey R., and Amy Finkelstein. 2008. "The Interaction of Public and Private Insurance: Medicaid and the Long-Term Care Insurance Market" American Economic Review, 98(3): 1083-1102.

Brown, Jeffrey R., and Amy Finkelstein. 2009. "The Private Market for Long-Term Care Insurance in the United States: A Review of the Evidence" Journal of Risk and Insurance, $76(1): 5-29$.

Brown, Jeffrey R., Norma B. Coe, and Amy Finkelstein. 2007. "Medicaid Crowd-Out of Private Long-Term Care Insurance Demand: Evidence from the Health and Retirement Survey" Tax Policy and the Economy, 21, 1-34.

CBO. 2004. "Financing Long-Term Care for the Elderly".

Chernew, Michael, and Arleen Leibowitz. 1992. "The Firm's Demand for Health Insurance" In Health Benefits and the Workforce, ed. U.S. Dept. of Labor Washington D.C. pp. 77-83. 
Chernew, Michael, Kevin Frick, and Catherine G. McLaughlin. 1997. "The Demand for Health Insurance Coverage by Low-Income Workers: Can Reduced Premiums Achieve Full Coverage?" Health Services Research, 32(4): 453-470.

Cohen, Marc A., Nanda Kumar, and Stanley S. Wallack. 1994. "Long-Term Care Insurance and Medicaid" Health Affairs, 13(4): 127-139.

Cohen, Marc, and Maurice Weinrobe. 2000. "Tax Deductibility of Long-Term Care Insurance Premiums" HIAA.

Corliss, Gary, Roger Gagne, Barry Koklefsky, Ronald Lucas, Susan Oberman-Smith, and Marianne Purushotham. 2007. "Society of Actuaries Long-Term Care Experience Committee Intercompany Study, 1984-2004".

Courtemanche, Charles, and Daifeng He. 2009. "Tax Incentives and the Decision to Purchase Long-Term Care Insurance" Journal of Public Economics.

Cramer, Anne T., and Gail A. Jensen. 2006. "Why Don't People Buy Long-Term-Care Insurance?" Journals of Gerontology Series B: Psychological Sciences and Social Sciences, 61(4): S185-193.

Currie, Janet, and Jonathan Gruber. 1996. "Saving Babies: The Efficacy and Cost of Recent Changes in the Medicaid Eligibility of Pregnant Women" Journal of Political Economy, 104(6): $1263-1296$.

Feenberg, Daniel, and Elisabeth Coutts. 1993. "An Introduction to the TAXSIM Model" Journal of Policy Analysis and Management, 12(1): 189-194.

Feldman, Roger, Bryan Dowd, Scott Leitz, and Lynn A. Blewett. 1997. "The Effect of Premiums on the Small Firm's Decision to Offer Health Insurance" Journal of Human Resources, 32(4): $635-658$.

Finkelstein, Amy. 2002. "The Effect of Tax Subsidies to Employer-Provided Supplementary Health Insurance: Evidence from Canada" Journal of Public Economics, 84(3): 305-339. 
Finkelstein, Amy, and Kathleen McGarry. 2006. "Multiple Dimensions of Private Information: Evidence from the Long-Term Care Insurance Market" American Economic Review, 96(4): 938-958.

Genworth. 2010. "Genworth Financial Cost of Care Survey".

Grabowski, David C., and Jonathan Gruber. 2007. "Moral Hazard in Nursing Home Use" Journal of Health Economics, 26(3): 560-577.

Grabowski, David C., Zhanlian Feng, Orna Intrator, and Vincent Mor. 2004. "Recent Trends In State Nursing Home Payment Policies" Health Affairs.

Gruber, Jonathan, and James Poterba. 1994. "Tax Incentives and the Decision to Purchase Health Insurance: Evidence from the Self-Employed" The Quarterly Journal of Economics, 109(3): 701-733.

Gruber, Jonathan, and Michael Lettau. 2004. "How Elastic is the Firm's Demand for Health Insurance?" Journal of Public Economics, 88(7-8): 1273-1293.

Johnson, Richard W., Simone G. Schaner, Desmond Toohey, and Cori E. Uccello. 2007. "Modeling the Decision to Purchase Long-Term Care Insurance".

Marquis, M. Susan, and Stephen H. Long. 1995. "Worker Demand for Health Insurance in the Non-Group Market" Journal of Health Economics, 14(1): 47-63.

Marquis, M. Susan, and Stephen H. Long. 2001. "To offer or not to offer: the role of price in employers' health insurance decisions." Health Services Research, 36(5): 935-958.

Mitchell, Olivia S., James M. Poterba, Mark J. Warshawsky, and Jeffrey R. Brown. 1999. "New Evidence on the Money's Worth of Individual Annuities" American Economic Review, 89(5): 1299-1318.

Newhouse, Joseph P. 2004. Pricing the Priceless: A Health Care Conundrum. MIT Press.

NHA. 2010. "National Health Expenditures by Type of Service and Source of Funds".

Norton, Edward C. 2000. "Long-Term Care" In Handbook of Health Economics, ed. A. J. Culyer and J. P. Newhouse, vol. 1 Elsevier Science. chapter 17, pp. 956-988. 
Royalty, Anne B. 2000. "Tax Preferences for Fringe Benefits and Workers' Eligibility for Employer Health Insurance" Journal of Public Economics, 75(2): 209-227.

Stevenson, David, Jocelyn Hsu, and Richard Frank. 2009. "Private Long-Term Care Insurance and State Tax Incentives" Inquiry, 46(3): 5-321.

Weissert, William G., Cynthia M. Cready, and James E. Pawelak. 2005. "The Past and Future of Home- and Community-Based Long-Term Care" The Milbank Quarterly.

Wiener, Joshua, Jane Tilly, and Susan Goldenson. 2000. "Federal and State Initiatives to Jump Start the Market for Private Long-term Care Insurance" Elder Law Journal, 8(1): 57-99.

Wiener, Joshua M., Lauren H. Illston, and Raymond J. Hanley. 1994. Sharing the Burden: Strategies For Public And Private Long-Term Care Insurance. Washington D.C.: Brookings Institution Press. 
Figure 1: Tax Incentive Generosity Over Time, 1996-2006
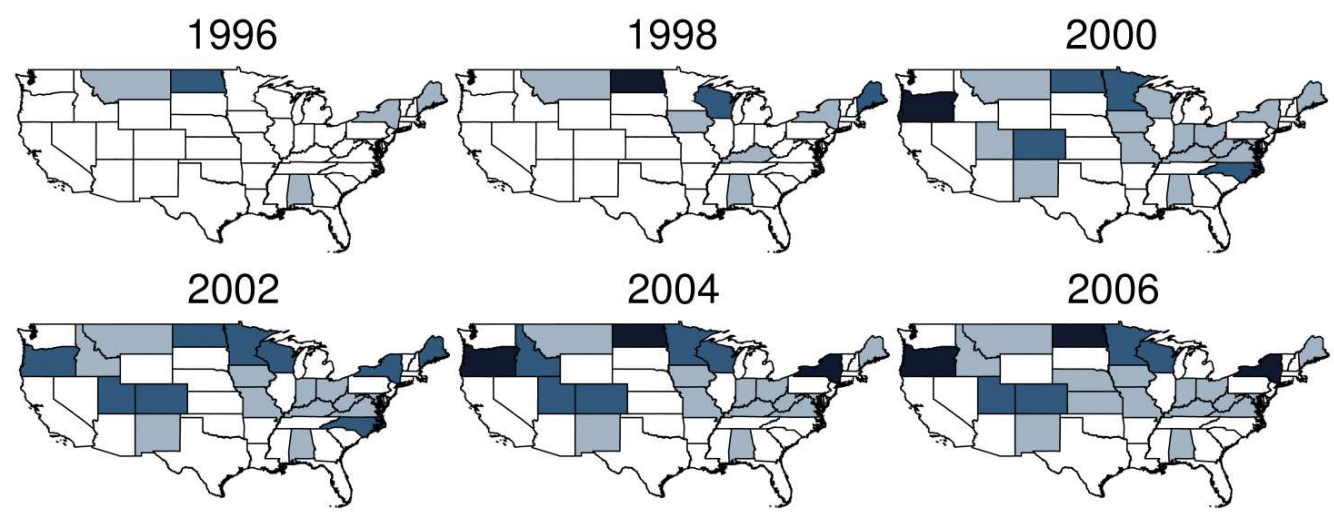

2006
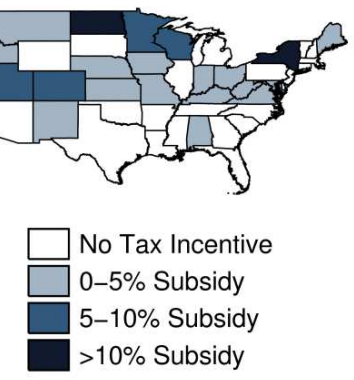

Source: Tax subsidy characteristics obtained from state tax forms. Average subsidy value calculated using sample from 1996-2006 waves of Health and Retirement Study (HRS) and NBER's TAXSIM calculator. See Appendix for more details.

Figure 2: Private Long-Term Care Insurance Coverage, Age 50-69

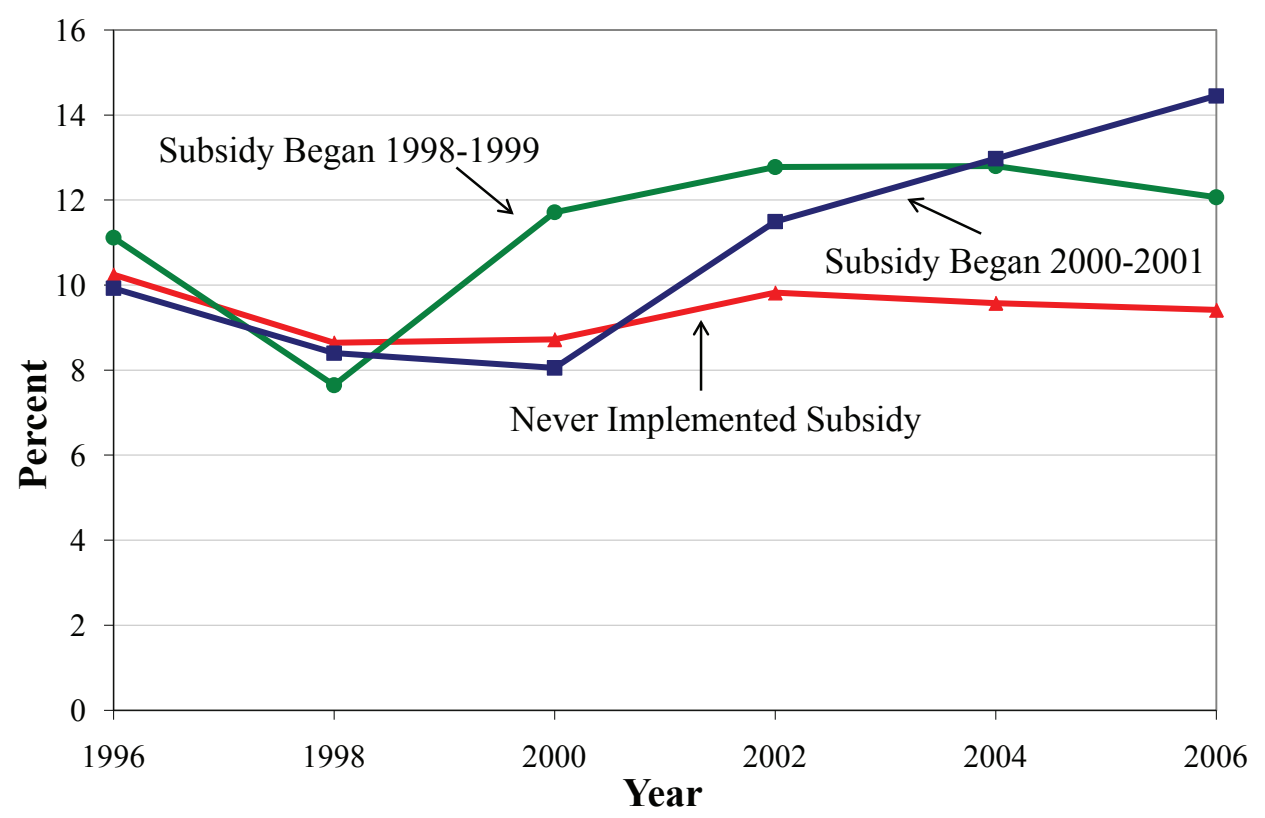

Source: Health and Retirement Study (HRS), Waves 3-8, 1996-2006. 
Figure 3: Estimated Net Benefit from Tax Subsidy for 65-Year-Olds by Wealth Decile

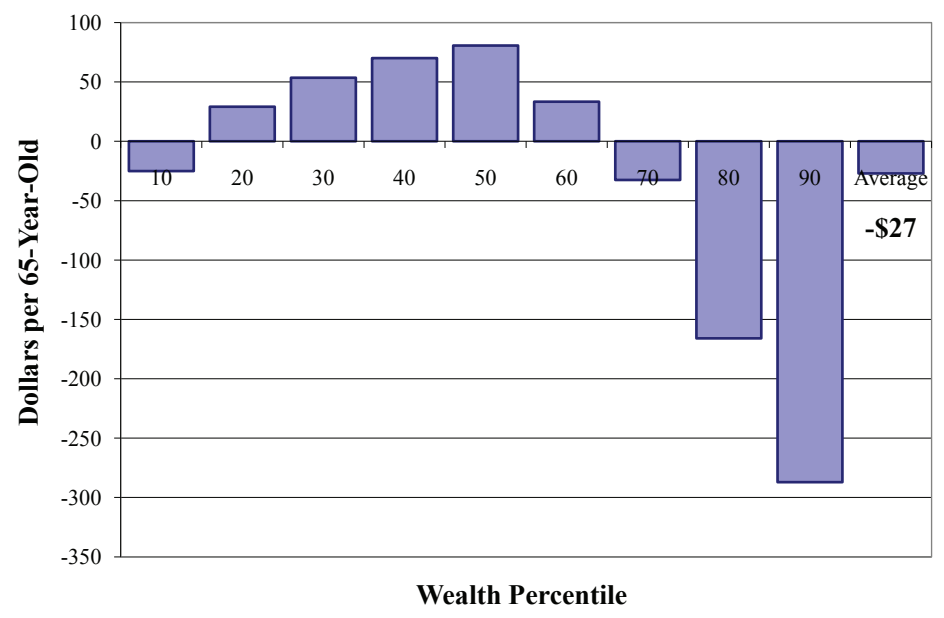

(a) Estimated Total Net Government Benefit

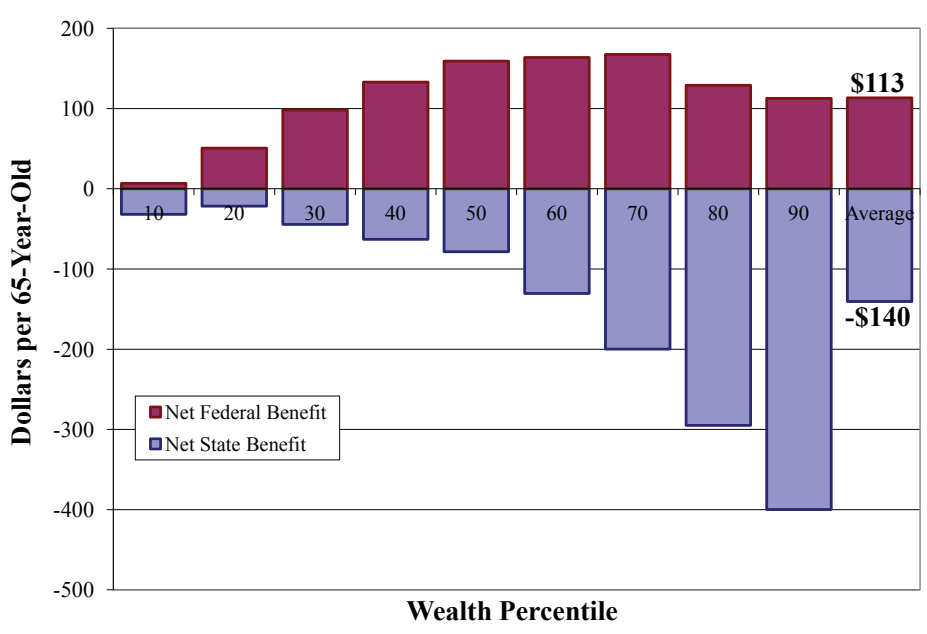

(b) Estimated Federal vs. State Net Government Benefit

Source: Author's calculations.

Notes: Calculations assume $\$ 2,000$ annual premium, 3 percent annual discount rate, EPDV of longterm care costs $=\$ 43,750$ for women and $\$ 17,510$ for men. Net benefits calculated as Medicaid savings less tax expenditure assuming average subsidy levels and response vary by wealth decile. In (b), Medicaid savings are assumed to be shared equally between federal and state governments and costs are borne by states. See Section 5 for additional details. 
Table 1: Summary Statistics: Individual-Level Control Variables

\begin{tabular}{lcccc}
\hline \hline & \multicolumn{2}{c}{$\begin{array}{c}\text { Do not have LTCI } \\
(\mathrm{N}=47,700)\end{array}$} & \multicolumn{2}{c}{$\begin{array}{c}\text { Have LTCI } \\
(\mathrm{N}=5,292)\end{array}$} \\
\cline { 2 - 5 } & Mean & Std Dev & Mean & Std Dev \\
\hline After-Tax Price & 0.986 & 0.040 & 0.982 & 0.044 \\
Any Subsidy Available & 0.280 & 0.449 & 0.334 & 0.472 \\
Credit Available & 0.108 & 0.311 & 0.140 & 0.347 \\
Deduction Available & 0.185 & 0.389 & 0.217 & 0.412 \\
HIPAA Subsidy Available & 0.117 & 0.321 & 0.189 & 0.391 \\
Income & 39,973 & 102,651 & 54,745 & 60,030 \\
Assets & 266,642 & $1,563,712$ & 446,441 & 931,397 \\
File Tax Return & 0.826 & 0.379 & 0.916 & 0.278 \\
Age & 59.27 & 5.18 & 59.96 & 5.28 \\
Female & 0.556 & 0.497 & 0.565 & 0.496 \\
Married & 0.690 & 0.463 & 0.763 & 0.425 \\
Some High School & 0.192 & 0.394 & 0.081 & 0.273 \\
High School & 0.374 & 0.484 & 0.318 & 0.466 \\
Some College & 0.231 & 0.422 & 0.244 & 0.429 \\
College Plus & 0.202 & 0.402 & 0.358 & 0.479 \\
Children & 3.103 & 2.023 & 2.824 & 1.871 \\
Hispanic & 0.084 & 0.277 & 0.029 & 0.169 \\
African-American & 0.111 & 0.314 & 0.074 & 0.262 \\
Other Race & 0.051 & 0.220 & 0.023 & 0.150 \\
Retired & 0.350 & 0.477 & 0.406 & 0.491 \\
Fair/Poor Health Status & 0.255 & 0.436 & 0.147 & 0.354 \\
\hline \hline
\end{tabular}

Source: Health and Retirement Study (HRS), Waves 3-8, 1996-2006. Observations at the person-year level weighted using individual-level weights. Income and assets expressed in constant 2006 dollars. Sample excludes individuals age 70 or older and those who report income from self-employment. 
Table 2: Private Long Term Care Insurance Coverage and Average Reduction in After-Tax Price

\begin{tabular}{|c|c|c|c|}
\hline & $\begin{array}{c}\text { Pre-Subsidy } \\
\text { LTCI } \\
\text { Coverage }\end{array}$ & $\begin{array}{l}\text { Average } \\
\text { Subsidy }\end{array}$ & $\mathrm{N}$ \\
\hline All & $9.5 \%$ & $4.6 \%$ & 52,992 \\
\hline \multicolumn{4}{|l|}{ Gender } \\
\hline Male & $9.5 \%$ & $4.8 \%$ & 21,448 \\
\hline Female & $9.5 \%$ & $4.5 \%$ & 31,544 \\
\hline \multicolumn{4}{|l|}{ Age } \\
\hline $50-59$ & $8.8 \%$ & $5.4 \%$ & 21,175 \\
\hline $60-69$ & $10.3 \%$ & $3.5 \%$ & 31,817 \\
\hline \multicolumn{4}{|l|}{ Education } \\
\hline High School or Less & $7.0 \%$ & $4.0 \%$ & 31,919 \\
\hline Some College or More & $12.6 \%$ & $5.3 \%$ & 21,073 \\
\hline \multicolumn{4}{|l|}{ Income } \\
\hline Low Income $(<\$ 15 \mathrm{~K})$ & $4.8 \%$ & $2.7 \%$ & 16,423 \\
\hline Medium Income $(\$ 15 \mathrm{~K}-\$ 40 \mathrm{~K})$ & $8.7 \%$ & $4.9 \%$ & 19,808 \\
\hline High Income $(>\$ 40 \mathrm{~K})$ & $13.7 \%$ & $5.7 \%$ & 16,761 \\
\hline \multicolumn{4}{|l|}{ Wealth } \\
\hline Low Wealth $(<\$ 20 \mathrm{~K})$ & $4.0 \%$ & $3.3 \%$ & 16,465 \\
\hline Medium Wealth $(\$ 20 \mathrm{~K}-\$ 150 \mathrm{~K})$ & $8.4 \%$ & $5.1 \%$ & 17,639 \\
\hline High Wealth $(>\$ 150 \mathrm{~K})$ & $14.7 \%$ & $5.1 \%$ & 18,888 \\
\hline \multicolumn{4}{|l|}{ Retirement Status } \\
\hline Working & $8.7 \%$ & $5.2 \%$ & 31,151 \\
\hline Retired & $11.0 \%$ & $3.7 \%$ & 21,841 \\
\hline \multicolumn{4}{|l|}{ Marital Status } \\
\hline Unmarried & $8.1 \%$ & $3.6 \%$ & 18,408 \\
\hline Married & $10.2 \%$ & $5.1 \%$ & 34,584 \\
\hline \multicolumn{4}{|l|}{ Self-Reported Health Status } \\
\hline Fair or Poor & $5.3 \%$ & $3.4 \%$ & 14,833 \\
\hline Good or Excellent & $11.0 \%$ & $5.0 \%$ & 38,159 \\
\hline \multicolumn{4}{|l|}{ ADL Limitations } \\
\hline None & $10.0 \%$ & $4.8 \%$ & 47,104 \\
\hline $1+$ & $5.2 \%$ & $2.7 \%$ & 5,888 \\
\hline
\end{tabular}

Source: Health and Retirement Study (HRS), Waves 3-8, 1996-2006. Sample constructed as described in Table 1. Average subsidy denotes average reduction in after-tax price for individuals in states with tax subsidy. 
Table 3: Linear Estimates of the Effect of Tax Subsidy Programs on Private Long-Term Care Insurance Coverage

\begin{tabular}{lcccc}
\hline \hline & $(1)$ & $(2)$ & $(3)$ & $(4)$ \\
\hline Subsidy & $0.023^{* *}$ & $0.028^{* *}$ & $0.024^{* *}$ & $0.027^{* * *}$ \\
& $(0.009)$ & $(0.011)$ & $(0.011)$ & $(0.009)$ \\
State + Year Fixed Effects & No & Yes & Yes & Yes \\
Control Variables & No & No & Yes & Yes \\
Individual Fixed Effects & No & No & No & Yes \\
\hline \hline
\end{tabular}

* significant at $10 \%$; ** significant at $5 \%$; *** significant at $1 \%$

Robust standard errors, clustered by states. Individual-level weights used. $\mathrm{N}=52,992$

Source: Health and Retirement Study (HRS), Waves 3-8, 1996-2006. Sample constructed as described in Table 1.

Notes: Each coefficient represents OLS estimates of Equation 1. The dependent variable is a binary variable denoting long-term care insurance coverage with an average value of 9.5 percent in states and years with no tax subsidy. The right-hand side variable SUBSIDY is a binary indicator for whether there is any tax subsidy in the state and year that the individual was sampled. The first column includes no additional right-hand side variables. Column (2) adds state and year fixed effects. Column (3) adds individual and state-level controls. Individual-level controls include education, gender, marital status, age, race, income, assets, number of children, retirement status, health status, and eligibility for federal tax subsidy through HIPAA. State-level controls include nursing facility occupancy rates, nursing home beds per 1,000 pop age $65+$, percent of state pop age $65+$, average nursing home private pay and Medicaid pay rate, Medicaid income/asset thresholds, spend down indicator. Column (4) adds individual fixed effects and omits time-invariant characteristics. 
Table 4: Linear Estimates of the Effect of the After-Tax Price on Private Long-Term Care Insurance Coverage

\begin{tabular}{lcccc}
\hline \hline & \multicolumn{3}{c}{ Panel A: Linear Probability Model } \\
& $(1)$ & $(2)$ & $(3)$ & $(4)$ \\
\hline After-Tax Price & $-0.276^{* * *}$ & $-0.192^{* *}$ & -0.103 & -0.037 \\
& $(0.083)$ & $(0.084)$ & $(0.070)$ & $(0.062)$ \\
Implied Elasticity with respect to After-Tax Price & -2.909 & -2.024 & -1.086 & -0.390 \\
& $(0.875)$ & $(0.885)$ & $(0.738)$ & $(0.654)$ \\
& \multicolumn{4}{c}{ Panel B: Instrumental Variables } \\
& $(1)$ & $(2)$ & $(3)$ & $(4)$ \\
\hline After-Tax Price & $-0.446^{* * *}$ & $-0.591^{* * *}$ & $-0.374^{* * *}$ & $-0.315^{* *}$ \\
& $(0.098)$ & $(0.140)$ & $(0.142)$ & $(0.158)$ \\
Implied Elasticity with respect to After-Tax Price & -4.702 & -6.230 & -3.943 & -3.321 \\
& $(1.033)$ & $(1.476)$ & $(1.497)$ & $(1.666)$ \\
& \multicolumn{4}{c}{} \\
F-Statistic for Test of Excluded Instrument & $3,471.16$ & $1,885.09$ & $2,070.89$ & $1,609.28$ \\
State + Year Fixed Effects & No & Yes & Yes & Yes \\
Control Variables & No & No & Yes & Yes \\
Individual Fixed Effects & No & No & No & Yes \\
\hline \hline
\end{tabular}

* significant at $10 \%$; $*$ significant at $5 \%$; ** significant at $1 \%$

Robust standard errors, clustered by individuals. Individual-level weights used. $\mathrm{N}=52,992$

Source: Health and Retirement Study (HRS), Waves 3-8, 1996-2006. Sample constructed as described in Table 1.

Notes: Each coefficient in Panel A represents OLS estimates of Equation 2. Each coefficient in Panel B represents IV estimates of Equation 2. The dependent variable is a binary variable denoting long-term care insurance coverage with an average value of 9.5 percent in states and years with no tax subsidy. The right-hand side variable TAXPRICE denotes the after-tax price of $\$ 1$ of private long-term care insurance in terms of foregone consumption. The instrument in Panel B is the average after-tax price for a nationally representative sample of 5,000 individuals within state X year X education cells. The first column includes no additional right-hand side variables. Column (2) adds state and year fixed effects. Column (3) adds individual and state-level controls. Individual-level controls include education, gender, marital status, age, race, income, assets, number of children, retirement status, health status, and eligibility for federal tax subsidy through HIPAA. State-level controls include nursing facility occupancy rates, nursing home beds per 1,000 pop age $65+$, percent of state pop age $65+$, average nursing home private pay and Medicaid pay rate, Medicaid income/asset thresholds, spend down indicator. Column (4) adds individual fixed effects and omits time-invariant characteristics. Implied elasticities computed as ratio of estimated coefficient to pre-subsidy insurance coverage rate. 
Table 5: Linear Estimates of the Effect of Tax Subsidy Programs on the Intensive Margin

\begin{tabular}{|c|c|c|c|c|}
\hline & \multicolumn{4}{|c|}{ "Panel A: Inflation Protection } \\
\hline & (1) & $(2)$ & $(3)$ & $(4)$ \\
\hline \multirow[t]{4}{*}{ Subsidy } & $0.013^{* *}$ & $0.014^{* *}$ & $0.014^{* *}$ & $0.012^{* *}$ \\
\hline & $(0.006)$ & $(0.007)$ & $(0.006)$ & $(0.006)$ \\
\hline & Panel B: & Jursing $\mathrm{F}$ & me $+\mathrm{H}$ & me Care \\
\hline & $(1)$ & $(2)$ & $(3)$ & $(4)$ \\
\hline \multirow[t]{2}{*}{ Subsidy } & $0.024^{* * *}$ & $0.029^{* *}$ & $0.025^{* *}$ & $0.025^{* *}$ \\
\hline & $(0.008)$ & $(0.011)$ & $(0.011)$ & $(0.009)$ \\
\hline State + Year Fixed Effects & No & Yes & Yes & Yes \\
\hline Control Variables & No & No & Yes & Yes \\
\hline Individual Fixed Effects & No & No & No & Yes \\
\hline
\end{tabular}

* significant at $10 \%$; ** significant at $5 \%$; ** significant at $1 \%$

Robust standard errors, clustered by states. Individual-level weights used. N=52,992

Source: Health and Retirement Study (HRS), Waves 3-8, 1996-2006. Sample constructed as described in Table 1.

Notes: Each coefficient represents OLS estimates of Equation 1. The dependent variable is a binary variable denoting long-term care insurance coverage with inflation protection (Panel A) with an average value of 3.9 percent or a binary variable denoting long-term care insurance coverage for both nursing home and home care (Panel B) with an average value of 7.1 percent. The right-hand side variable SUBSIDY is a binary indicator for whether there is any tax subsidy in the state and year that the individual was sampled. The first column includes no additional right-hand side variables. Column (2) adds state and year fixed effects. Column (3) adds individual and state-level controls. Individual-level controls include education, gender, marital status, age, race, income, assets, number of children, retirement status, health status, and eligibility for federal tax subsidy through HIPAA. State-level controls include nursing facility occupancy rates, nursing home beds per 1,000 pop age $65+$, percent of state pop age $65+$, average nursing home private pay and Medicaid pay rate, Medicaid income/asset thresholds, spend down indicator. Column (4) adds individual fixed effects and omits time-invariant characteristics. 
Table 6: Heterogeneity in Effect of Tax Subsidies Across Selected Subsamples

\begin{tabular}{|c|c|c|c|c|c|}
\hline & \multicolumn{2}{|c|}{ State FEs } & \multicolumn{2}{|c|}{ Individual FEs } & \multirow[b]{2}{*}{$\mathrm{N}$} \\
\hline & Coeff. & SE & Coeff. & $\mathrm{SE}$ & \\
\hline All & $0.024^{* *}$ & $(0.011)$ & $0.027^{* * *}$ & $(0.009)$ & 52,992 \\
\hline \multicolumn{6}{|l|}{ Gender } \\
\hline Male & $0.034^{*}$ & $(0.018)$ & $0.031^{*}$ & $(0.015)$ & 21,448 \\
\hline Female & $0.017^{*}$ & $(0.009)$ & $0.023^{* * *}$ & $(0.009)$ & 31,544 \\
\hline \multicolumn{6}{|l|}{ Age } \\
\hline $50-59$ & $0.025^{*}$ & $(0.015)$ & $0.031^{*}$ & $(0.016)$ & 21,175 \\
\hline $60-69$ & $0.032^{* *}$ & $(0.012)$ & $0.025^{* *}$ & $(0.012)$ & 31,817 \\
\hline \multicolumn{6}{|l|}{ Education } \\
\hline High School or Less & 0.006 & $(0.008)$ & $0.015^{*}$ & $(0.008)$ & 31,919 \\
\hline Some College or More & $0.046^{* * *}$ & $(0.017)$ & $0.045^{* * *}$ & $(0.015)$ & 21,073 \\
\hline \multicolumn{6}{|l|}{ Income } \\
\hline Low Income $(<\$ 15 \mathrm{~K})$ & -0.002 & $(0.008)$ & -0.010 & $(0.009)$ & 16,423 \\
\hline Medium Income $(\$ 15 \mathrm{~K}-\$ 40 \mathrm{~K})$ & 0.016 & $(0.013)$ & 0.018 & $(0.012)$ & 19,808 \\
\hline High Income $(>\$ 40 \mathrm{~K})$ & $0.052^{* * *}$ & $(0.018)$ & $0.064 * * *$ & $(0.016)$ & 16,761 \\
\hline \multicolumn{6}{|l|}{ Wealth } \\
\hline Low Wealth $(<\$ 20 \mathrm{~K})$ & -0.002 & $(0.012)$ & 0.006 & $(0.013)$ & 16,465 \\
\hline Medium Wealth $(\$ 20 \mathrm{~K}-\$ 150 \mathrm{~K})$ & $0.020 *$ & $(0.010)$ & $0.025^{* *}$ & $(0.010)$ & 17,639 \\
\hline High Wealth $(>\$ 150 \mathrm{~K})$ & $0.047 * *$ & $(0.020)$ & $0.042^{* *}$ & $(0.018)$ & 18,888 \\
\hline \multicolumn{6}{|l|}{ Retirement Status } \\
\hline Working & 0.021 & $(0.014)$ & $0.029 * *$ & $(0.012)$ & 31,151 \\
\hline Retired & $0.030 * * *$ & $(0.010)$ & $0.017^{* *}$ & $(0.008)$ & 21,841 \\
\hline \multicolumn{6}{|l|}{ Marital Status } \\
\hline Unmarried & 0.000 & $(0.015)$ & $0.018^{*}$ & $(0.010)$ & 18,408 \\
\hline Married & $0.037 * * *$ & $(0.013)$ & $0.030 * *$ & $(0.012)$ & 34,584 \\
\hline \multicolumn{6}{|l|}{ Self-Reported Health Status } \\
\hline Good or Excellent & $0.033^{* *}$ & $(0.013)$ & $0.029 * *$ & $(0.011)$ & 38,159 \\
\hline Fair or Poor & -0.002 & $(0.006)$ & $0.014^{*}$ & $(0.008)$ & 14,833 \\
\hline \multicolumn{6}{|l|}{ ADL Limitations } \\
\hline None & $0.026^{* *}$ & $(0.011)$ & $0.028^{* * *}$ & $(0.010)$ & 47,104 \\
\hline $1+$ & 0.003 & $(0.015)$ & 0.010 & $(0.019)$ & 5,888 \\
\hline
\end{tabular}

* denotes significantly different from zero (* significant at $10 \%$; ** significant at $5 \%$; ${ }^{* * *}$ significant at $1 \%$ ); bold denotes significantly different from top category at $10 \%$ level or lower

Source: Health and Retirement Study (HRS), Waves 3-8, 1996-2006. Sample constructed as described in Table 1.

Notes: Each coefficient represents OLS estimates of Equation 1. The dependent variable is a binary variable denoting long-term care insurance coverage. Average values by demographic group summarized in Table 2. The right-hand side variable $S U B S I D Y$ is a binary indicator for whether there is any tax subsidy in the state and year that the individual was sampled. Column (1) includes state and year fixed effects and individual and state-level controls. Column (2) adds individual fixed effects and omits time-invariant characteristics. Individual-level controls include education, gender, marital status, age, race, income, assets, number of children, retirement status, health status, and eligibility for federal tax subsidy through HIPAA. State-level controls include nursing facility occupancy rates, nursing home beds per 1,000 pop age $65+$, percent of state pop age $65+$, average nursing home private pay and Medicaid pay rate, Medicaid income/asset thresholds, spend down indicator. Eaç category represents a separate regression including interactions between subgroup indicators and all other right-hand side variables. 
Table 7: Heterogeneity in Price Elasticities Across Selected Subsamples

\begin{tabular}{|c|c|c|c|c|c|}
\hline & \multicolumn{2}{|c|}{ State FEs } & \multicolumn{2}{|c|}{ Individual FEs } & \multirow[b]{2}{*}{$\mathrm{N}$} \\
\hline & Coeff. & $\mathrm{SE}$ & Coeff. & $\mathrm{SE}$ & \\
\hline All & $-3.943^{* *}$ & $(1.497)$ & $-3.321^{* * *}$ & $(1.666)$ & 52,992 \\
\hline \multicolumn{6}{|l|}{ Gender } \\
\hline Male & $-4.046^{*}$ & $(2.188)$ & -1.753 & $(2.409)$ & 21,448 \\
\hline Female & $-4.042^{* *}$ & $(2.049)$ & $-4.705^{* *}$ & $(2.269)$ & 31,544 \\
\hline \multicolumn{6}{|l|}{ Age } \\
\hline $50-59$ & -3.231 & $(2.332)$ & -2.615 & $(2.615)$ & 21,175 \\
\hline $60-69$ & $-6.244^{* * *}$ & $(2.139)$ & $-4.166^{* *}$ & $(3.521)$ & 31,817 \\
\hline \multicolumn{6}{|l|}{ Education } \\
\hline High School or Less & -0.915 & $(2.219)$ & -1.086 & $(2.371)$ & 31,919 \\
\hline Some College or More & $-4.432 * * *$ & $(1.687)$ & $-4.106^{* *}$ & $(1.987)$ & 21,073 \\
\hline \multicolumn{6}{|l|}{ Income } \\
\hline Low Income $(<\$ 15 \mathrm{~K})$ & 6.845 & $(5.665)$ & 10.691 & $(7.096)$ & 16,423 \\
\hline Medium Income $(\$ 15 \mathrm{~K}-\$ 40 \mathrm{~K})$ & -0.473 & $(1.933)$ & 1.397 & $(2.595)$ & 19,808 \\
\hline High Income $(>\$ 40 \mathrm{~K})$ & $-6.036 * * *$ & $(1.800)$ & $-6.473 * * *$ & $(1.792)$ & 16,761 \\
\hline \multicolumn{6}{|l|}{ Wealth } \\
\hline Low Wealth $(<\$ 20 \mathrm{~K})$ & 6.286 & $(5.351)$ & 2.204 & $(5.345)$ & 16,465 \\
\hline Medium Wealth $(\$ 20 \mathrm{~K}-\$ 150 \mathrm{~K})$ & -1.302 & $(2.377)$ & -1.539 & $(2.961)$ & 17,639 \\
\hline High Wealth $(>\$ 150 \mathrm{~K})$ & $-5.522 * * *$ & $(1.734)$ & $-4.220 * *$ & $(1.751)$ & 18,888 \\
\hline \multicolumn{6}{|l|}{ Retirement Status } \\
\hline Working & $-4.701^{* *}$ & $(2.012)$ & $-3.858^{*}$ & $(2.188)$ & 31,151 \\
\hline Retired & -2.547 & $(2.130)$ & -1.469 & $(2.142)$ & 21,841 \\
\hline \multicolumn{6}{|l|}{ Marital Status } \\
\hline Unmarried & -0.443 & $(3.132)$ & -5.242 & $(4.266)$ & 18,408 \\
\hline Married & $-5.070 * * *$ & $(1.662)$ & -2.535 & $(1.725)$ & 34,584 \\
\hline \multicolumn{6}{|l|}{ Self-Reported Health Status } \\
\hline Good or Excellent & $-9.889^{* * *}$ & $(3.008)$ & $-7.131^{* *}$ & $(3.347)$ & 38,159 \\
\hline Fair or Poor & 3.389 & $(2.679)$ & 0.537 & $(3.103)$ & 14,833 \\
\hline \multicolumn{6}{|l|}{ ADL Limitations } \\
\hline None & $-4.411^{* * *}$ & $(1.489)$ & $-3.679 * *$ & $(1.659)$ & 47,104 \\
\hline $1+$ & $15.787 * *$ & $(7.816)$ & 13.592 & $(9.227)$ & 5,888 \\
\hline
\end{tabular}

* denotes significantly different from zero (* significant at $10 \%$; ** significant at $5 \%$; ${ }^{* *}$ significant at $1 \%$ ); bold denotes significantly different from top category at $10 \%$ level or lower

Source: Health and Retirement Study (HRS), Waves 3-8, 1996-2006. Sample constructed as described in Table 1.

Notes: Each value represents implied elasticity computed using IV estimates of Equation 2 as described in Table 4 estimated separately for each subgroup and coverage rates from Table 2. Column (1) includes state and year fixed effects and individual and state-level controls. Column (2) adds individual fixed effects and omits time-invariant characteristics. Individual-level controls include education, gender, marital status, age, race, income, assets, number of children, retirement status, health status, and eligibility for federal tax subsidy through HIPAA. State-level controls include nursing facility occupancy rates, nursing home beds per 1,000 pop age $65+$, percent of state pop age $65+$, average nursing home private pay and Medicaid pay rate, Medicaid income/asset thresholds, spend down indicator. 
Table 8: Descriptive Statistics for Population, LTCI Purchasers, and Tax-Induced LTCI Purchasers

\begin{tabular}{lccccccc}
\hline \hline & & \multicolumn{3}{c}{ Tax-Induced } \\
Characteristic & $(1)$ & $(2)$ & $(3)$ & $(3)-(1)$ & $(3)-(2)$ \\
\hline Age & 59.34 & 59.96 & 59.82 & 0.47 & & -0.14 \\
Income & 41,471 & 54,745 & 67,868 & 26,397 & $* *$ & 13,123 & \\
Assets & 284,872 & 446,441 & 953,678 & 668,806 & $* * *$ & 507,237 & $* * *$ \\
Female & 0.557 & 0.565 & 0.672 & 0.115 & & 0.107 & \\
Married & 0.697 & 0.763 & 0.976 & 0.279 & $* * *$ & 0.213 & $* * *$ \\
Some High School & 0.181 & 0.081 & 0.052 & -0.129 & $* * *$ & -0.028 & \\
High School & 0.369 & 0.318 & 0.171 & -0.198 & $* *$ & -0.147 & $*$ \\
Some College & 0.232 & 0.244 & 0.037 & -0.195 & $* *$ & -0.206 & $* *$ \\
College Plus & 0.218 & 0.358 & 0.740 & 0.521 & $* * *$ & 0.382 & $* * *$ \\
Children & 3.075 & 2.824 & 2.758 & -0.316 & & -0.065 & \\
Hispanic & 0.078 & 0.029 & -0.089 & -0.167 & $* * *$ & -0.118 & $* * *$ \\
African-American & 0.107 & 0.074 & -0.035 & -0.142 & $* * *$ & -0.109 & $* * *$ \\
Other Race & 0.048 & 0.023 & -0.032 & -0.080 & $* * *$ & -0.055 & $* *$ \\
Retired & 0.356 & 0.406 & 0.460 & 0.104 & & 0.054 & \\
Fair/Poor Health Status & 0.244 & 0.147 & 0.071 & -0.174 & $* * *$ & -0.076 & \\
\hline \hline
\end{tabular}

* significant at $10 \%$; ** significant at $5 \%$; ** significant at $1 \%$. Individual-level weights used. $\mathrm{N}=52,992$

Source: Health and Retirement Study (HRS), Waves 3-8, 1996-2006. Sample constructed as described in Table 1.

Notes: The sample mean among tax-induced purchasers in Column (3) is calculated as described in Equation 3. Standard errors of the differences are calculated using STATA's bootstrap package with resampling performed 1,000 times. 
Table 9: Linear Estimates of the Effect of Tax Subsidy Programs on Alternative Insurance Coverage

\begin{tabular}{lcccc}
\hline \hline & \multicolumn{5}{c}{ Panel A: Life Insurance } \\
& $(1)$ & $(2)$ & $(3)$ & $(4)$ \\
\hline Subsidy & 0.020 & 0.013 & 0.014 & $0.018^{*}$ \\
& $(0.028)$ & $(0.015)$ & $(0.013)$ & $(0.011)$ \\
& \multicolumn{5}{c}{ Panel B: Receiving } & Annuity & Income \\
& $(1)$ & $(2)$ & $(3)$ & $(4)$ \\
\hline Subsidy & 0.000 & -0.005 & -0.005 & -0.003 \\
& $(0.002)$ & $(0.004)$ & $(0.004)$ & $(0.004)$ \\
State + Year Fixed Effects & No & Yes & Yes & Yes \\
Control Variables & No & No & Yes & Yes \\
Individual Fixed Effects & No & No & No & Yes \\
\hline \hline
\end{tabular}

* significant at $10 \% ; * *$ significant at $5 \%$; ** significant at $1 \%$

Robust standard errors, clustered by states. Individual-level weights used. $\mathrm{N}=52,992$

Source: Health and Retirement Study (HRS), Waves 3-8, 1996-2006. Sample constructed as described in Table 1.

Notes: Each coefficient represents OLS estimates of Equation 1 with alternative insurance coverage on the left-hand side. The dependent variable is a binary variable denoting ownership of non-cash value life insurance (Panel A) with an average value of 68.0 percent or a binary variable denoting receipt of income from an annuity (Panel B) with an average value of 1.6 percent. The right-hand side variable SUBSIDY is a binary indicator for whether there is any tax subsidy for private long-term care insurance in the state and year that the individual was sampled. The first column includes no additional right-hand side variables. Column (2) adds state and year fixed effects. Column (3) adds individual and state-level controls. Individual-level controls include education, gender, marital status, age, race, income, assets, number of children, retirement status, health status, and eligibility for federal tax subsidy through HIPAA. State-level controls include nursing facility occupancy rates, nursing home beds per 1,000 pop age 65+, percent of state pop age $65+$, average nursing home private pay and Medicaid pay rate, Medicaid income/asset thresholds, spend down indicator. Column (4) adds individual fixed effects and omits time-invariant characteristics. 
Table 10: Medicaid Share of Expected Present Discounted Value of Total Long-Term Care Expenditures for 65-Year-Old by Gender and Wealth

\begin{tabular}{ccccc}
\hline \hline \multirow{2}{*}{ Wealth } & \multicolumn{2}{c}{ Men } & \multicolumn{2}{c}{ Women } \\
\cline { 2 - 5 } Percentile & No Private & With Private & No Private & With Private \\
$i$ & $M_{i, m}(N)$ & $M_{i, m}(I)$ & $M_{i, f}(N)$ & $M_{i, f}(I)$ \\
\hline 10th & 0.98 & 0.52 & 0.99 & 0.55 \\
20 th & 0.89 & 0.44 & 0.93 & 0.50 \\
30th & 0.80 & 0.41 & 0.88 & 0.46 \\
40th & 0.71 & 0.37 & 0.80 & 0.43 \\
50 th & 0.60 & 0.32 & 0.72 & 0.38 \\
60 th & 0.46 & 0.26 & 0.60 & 0.33 \\
70 th & 0.32 & 0.20 & 0.45 & 0.24 \\
80th & 0.17 & 0.12 & 0.24 & 0.15 \\
90 th & 0.07 & 0.05 & 0.08 & 0.06 \\
\hline \hline
\end{tabular}

Source: Brown and Finkelstein (2008), Table 2. 


\section{Appendix A: State Tax Subsidies for Private Long-Term Care Insurance}

In 2006, fifteen states allowed taxpayers to deduct premiums from their income, six states offered tax credits, and two states offered both. The credits are not refundable, and therefore may only be used to offset existing tax liabilities. Their values are generally capped at a specific dollar amount or proportion of premium, and tend to be more generous than subsidies arising from premium deductions. Tax incentives in the form of deductions are in most cases allowable in addition to the standard deduction, not requiring taxpayers to itemize their deductions.

\begin{tabular}{|c|c|c|c|}
\hline State & Year Started & Credit & Deduction \\
\hline Alabama & 1995 & & $\checkmark$ \\
\hline Colorado & 2000 & $\checkmark$ & \\
\hline District of Columbia & 2005 & & $\checkmark$ \\
\hline Idaho & 2001 & & $\checkmark$ \\
\hline Indiana & 2000 & & $\checkmark$ \\
\hline Iowa & 1997 & & $\checkmark$ \\
\hline Kansas & 2005 & & $\checkmark$ \\
\hline Kentucky & 1998 & & $\checkmark$ \\
\hline Maine & 1990 & & $\checkmark$ \\
\hline Maryland & 2000 & $\checkmark$ & \\
\hline Minnesota & 1999 & $\checkmark$ & \\
\hline Missouri & 2000 & & $\checkmark$ \\
\hline Montana & 1992 & & $\checkmark$ \\
\hline Nebraska & 2006 & & $\checkmark$ \\
\hline New Mexico & 2000 & & $\checkmark$ \\
\hline New York ${ }^{a}$ & 1996 & $\checkmark$ & $\checkmark$ \\
\hline North Carolina $^{b}$ & 1999 & $\checkmark$ & \\
\hline North Dakota & 1994 & $\checkmark$ & $\checkmark$ \\
\hline Ohio & 1999 & & $\checkmark$ \\
\hline Oregon & 2000 & $\checkmark$ & \\
\hline Utah & 2000 & & $\checkmark$ \\
\hline Virginia & 2000 & $\checkmark$ & $\checkmark$ \\
\hline West Virginia & 2000 & & $\checkmark$ \\
\hline Wisconsin & 1998 & & $\checkmark$ \\
\hline
\end{tabular}

${ }^{a}$ New York provided a tax deduction of long-term care insurance premiums from 1996 through 2001, and a credit from 2002 onwards.

${ }^{b}$ North Carolina implemented a credit in 1999 available through 2003; a modified version was subsequently reinstated in tax year 2007. 


\section{Appendix B: Calculation of After-Tax Price}

Calculation of the after-tax price of $\$ 1$ of long-term care insurance was performed using each state's description of the tax incentive and often required calculation of the individual's marginal tax rate. Marginal tax rate simulations were done using NBER's TAXSIM program (Feenberg and Coutts, 1993).

\section{Simulations of marginal tax rates}

The RAND version of the HRS was used, merged with additional variables from the HRS. A mapping of the financial variables in the HRS to TAXSIM input is provided below.

\begin{tabular}{|c|c|c|}
\hline TAXSIM input & Description & HRS Variable(s) used \\
\hline pwages & Wage income of primary taxpayer & Individual earnings \\
\hline swages & Wage income of secondary taxpayer & Individual earnings of spouse \\
\hline dividends & Dividend income & Included in household capital income \\
\hline otherprop & Interest and other property income & Other household income \\
\hline pensions & Taxable pension income & $\begin{array}{l}\text { Respondent's and spouse's pension } \\
\text { income }\end{array}$ \\
\hline gssi & Gross social security benefits & $\begin{array}{l}\text { Respondent's and spouse's Social } \\
\text { Security retirement and disability } \\
\text { income }\end{array}$ \\
\hline transfers & Non-taxable transfer income & $\begin{array}{l}\text { Respondent's and spouse's other } \\
\text { government transfers }\end{array}$ \\
\hline rentpaid & Rent paid & Rent paid \\
\hline proptax & Property tax paid & Property tax paid \\
\hline otheritem & Other itemized deductions & $\begin{array}{l}\text { Charitable donations and itemizable } \\
\text { medical expenses }\end{array}$ \\
\hline childcare & Child care expenses & Imputed as zero \\
\hline ui & Unemployment compensation benefits & $\begin{array}{l}\text { Respondent's and spouse's unemployment } \\
+ \text { + workers compensation benefits }\end{array}$ \\
\hline mortgage & Mortgage interest paid & $\begin{array}{l}\text { Outstanding mortgage amount * } \\
6 \text { percent }\end{array}$ \\
\hline stcg & Short term capital gain/loss & Household capital income \\
\hline $\operatorname{ltcg}$ & Long term capital gain/loss & Imputed as zero \\
\hline
\end{tabular}

\section{Imputation of after-tax price}

The first step in the imputation of an individual's after-tax price was to assign each person a premium amount based on their state, year, and age. The premium amounts came from Table 5-4 in Johnson et al. (2007), which summarizes Weiss Ratings, Inc. premium data from 2002. 
Premiums for ages that were not reported were interpolated from the available data and premiums were assumed to grow by 3 percent each year.

Next, a credit value and deduction value was calculated for each person. If a state had a tax credit for long-term care insurance, the credit value was determined by the following formula:

$$
C=\max \left(\min \left(\min \left(c_{s} \times \pi, \bar{c}_{s}\right), T_{s}\right), 0\right)
$$

where $c$ is the fraction of the premium payable as a credit, $\pi$ is the premium, and $\bar{c}_{s}$ is the maximum dollar amount of the credit. The value of the credit is constrained to be between zero and the individual's state tax liability, $T_{s}$, because the credits are nonrefundable. Similarly, the value of a deduction in states with a deduction is given by:

$$
D=\max \left(\min \left(d_{s} \times \pi, \bar{d}_{s}\right) \times \tau_{s}, 0\right)
$$

where $d_{s}$ is the fraction of the premium deductible, $\tau_{s}$ is the individual's state marginal tax rate, and $\bar{d}_{s}$ is the maximum amount deductible. Where the tax incentives differed by age or income, appropriate adjustments were made. For individuals who itemize their expenses, the subsidy value was reduced by their federal marginal tax rate to account for the deductibility of state income taxes. For individuals who did not file a tax return, the after-tax price was set to 1 . Therefore, the after-tax price $T A X P R I C E$ is given by:

$$
\text { TAXPRICE }= \begin{cases}1 & \text { if non-tax filer } \\ \frac{\pi-(C+D)\left(1-\tau_{f}\right)}{\pi} & \text { if itemizer } \\ \frac{\pi-(C+D)}{\pi} & \text { otherwise }\end{cases}
$$

